
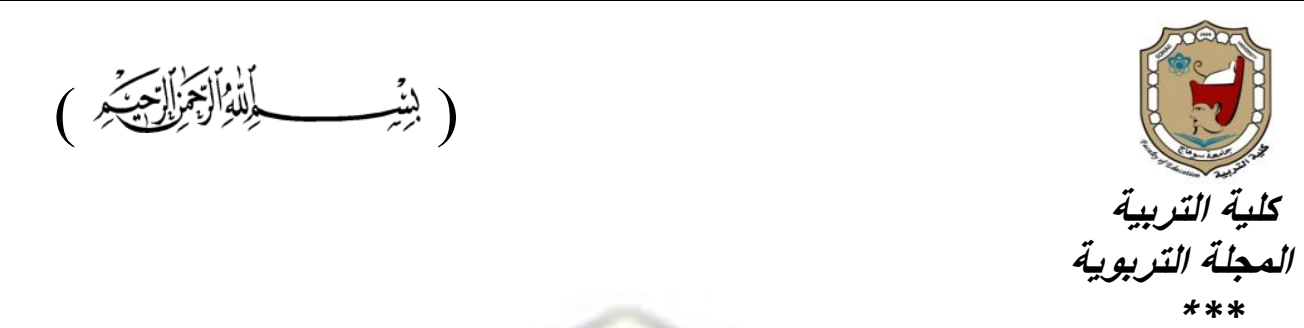

تقويهم ههارات الفهم القرائي في البرناهج القرائي لكتاب اللغة العربية بالصف الأول الثانوي التجاري على ضوء المعايير الدولية للتنور القرائي PIRLS

\title{
إعداد
}

أ.م.د /ذجلاي يوسف يوسف حواس

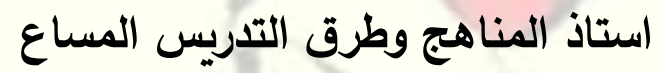

كلية التربية ببورسعيد - جامعة بور سعيد الفريد الكساع

DOI: $1 . .1 \uparrow \wedge 1 \%$ EDUSOHAG. $r . \uparrow$.

$$
\text { المجلة التربوية.العدد السبعون ـ فبراير.r.r.r. }
$$

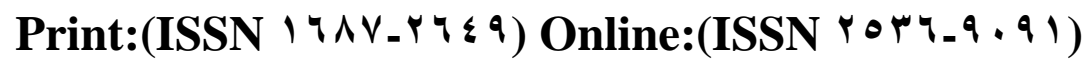


مستخلص

هدف البحث إلى تحديد مهارات الفهم القرائي المتضمنة في البرنامج القرائي لكتاب اللغة العربية بالصف الأول الثانوي التجاري في ضوء المعايير الدولية للتنور القرائي ، وقد اتبع البحث المنهج الوصفي التحليلي وقد توصل البحث لقائمة مهارات الفهم القرائي اللازمة للمرحلة الثانوية ووضعت القائمة في ضوء المعايير الدولية للتنور القرائي واحتوت القائمة

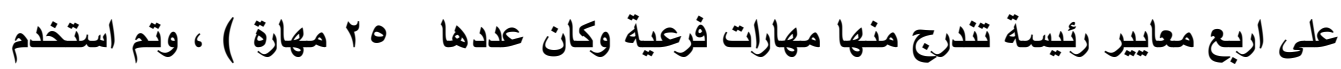
بطاقة تحليل المحتوى كأداة لتحقيق هدف البحث وطبقت على المحتوى القرائي للفصلين الأول والثاني من كتاب اللغة العربية لطلاب الصف الأول الثانوي . وفى ضوء نتائج البحث جاءت مهارات الفهم القرائي بنسب متفاوتة ، حيث نالت مهارات استرجاع المعلومات على أعلى مستوى وجاءت بنسب ضعيفة فى البرنامج القرائي مهارات (دمج الأفكار وتفسير المعلومات-- تقويم المحتوى واللغة والعناصر) وافتقر البرنامج لمهارات تكوين الاستدلالات وفى ضوء ما أسفر عنه البحث ، قدمت الباحثة تصور مقترح لتضمين مهارات الفهح القرائي بالبرنامج القرائي في ضوء معايير التنور القرائي كمحاولة لعلاج نواحي القصور. الكلمات المفتاحية : ( الفهم القرائي - البرنامج القرائى- التنور القرائي ) 
تقويم مهارات الفهم القرائي في البرنامج القرائي لكتاب اللغة العربية بالصف الأول الثانوي التجاري.

Evaluation of Reading Comprehension Skills in the Reading Program of Arabic Book for First Grade Commercial Secondary in the Light of the International Standards for Measuring Reading Literacy PIRLS

\begin{abstract}
:
The research aimed at determining the reading comprehension skills of the reading program of Arabic textbook for first-grade commercial secondary in the light of the international standards for measuring reading literacy. The research utilized the descriptive analytical approach to develop a list of reading comprehension skills required for the secondary stage considering the standards of PIRLS. The list encompassed four main criteria for twenty-five sub-skills. The current researcher used a content analysis checklist for analyzing the reading content of the Arabic textbook for first-grade secondary students of two semesters. The results indicated that the program focused mainly on information retrieval skills, while other skills such as synthesizing ideas, interpreting information, and evaluating the content and the language were inadequately handled, in addition to completely lacking inference skills. Based on the findings, the researcher provided a proposal for incorporating the skills of reading comprehension in the reading program in light of the standards of reading literacy as an attempt to address the shortcomings.
\end{abstract}

Keywords: reading comprehension, reading program, reading literacy 
مقدمة

يثهد العصر الحالي تقدما علميا وإنفجارا معرفيا سريعا ومتلاحقا في جميع ميادين

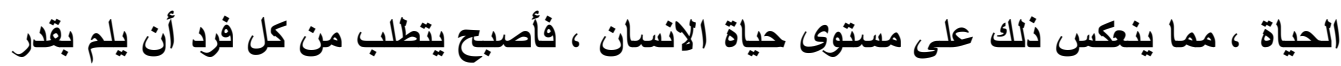

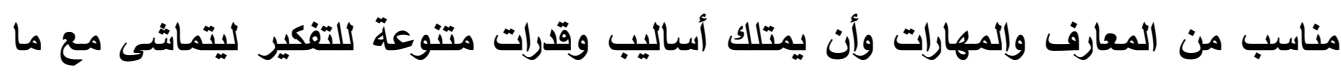

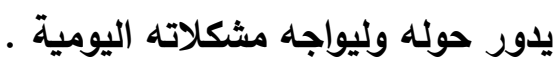
وحتى يتكيف ويتماثى الفرد مع طبيعة العصر ومتطلباته ، ينبغي أن يكون متنورا

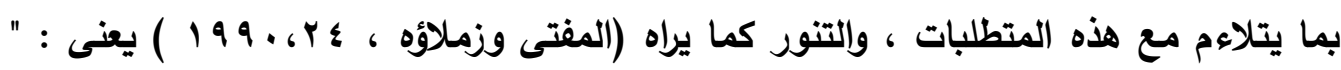
الطرائق والأساليب التي يعبر بها الإنسان عن إدراكه للعالم ، وعن أدوار كينونته فيه ، فهو

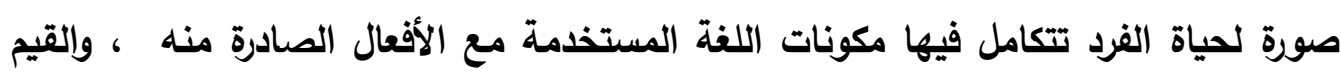
والمعتقات التي يتبناها ويؤمن بها ، والمعارف التي اكتسبها والاتجاهات والثهوايات الاجتماعية التي يتميز بها عن غيره من البشر بصفة عامة ، وعن غيره التهن من أبناء ثقافته بصفة خاصة " يرتبط أهمية التنور العام للفرد في هذا العصر إلى حاجتنا الماسة إلى أفراد متعلمين يلمون بحد أدنى من المعرفة ، متنورين وتطبيقاً لهذا التصور فإن علمطا التربية

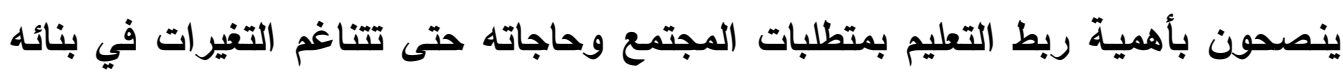

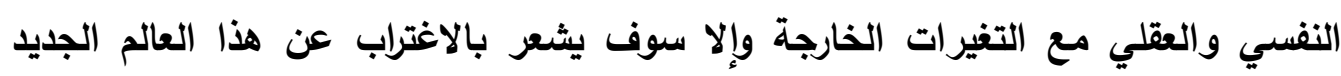

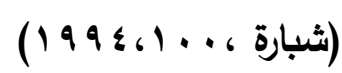

وتعد التربية هي أحد مصادر تمكن الافراد من ملاحقة هذه التطورات وإعداد فرد

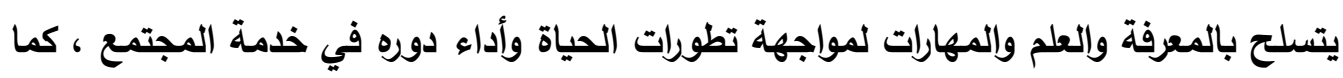
تسهم في تزويده بالمعرفة في موضوعات ومجالات علمية متعددة ومتنوعة .

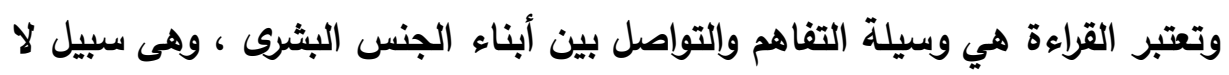

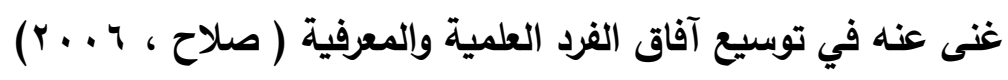

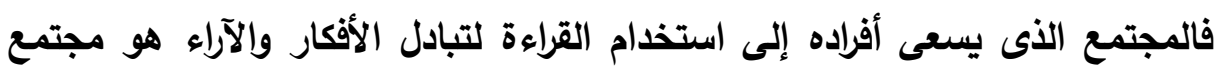
يحمل صفة القوة الفكرية لأفراده ومجتمع قادر دوما على التقدم والازدهار في شتى مجالات الحياة . 


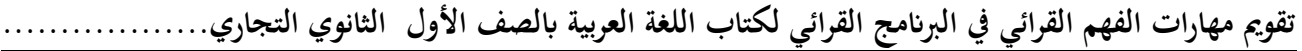

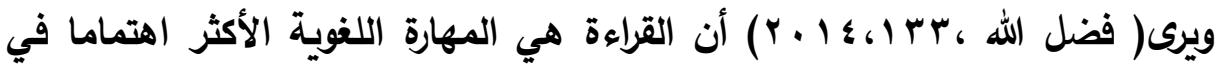

العمل المدرسي ، سواء كان هذا العمل موجها من خلال حصة القراءة وكتبها داخل الفصل أو الو في المكتبة ، أو خارج المدرسة في أوقات الفراغ لتوسيع دائرة معارف وخبرات التلاميذ وتهذيب أذواقهم وتنشيط أفكارهم .

لذا أصبح من الضروري بناء قارئ وإع يتجاوز مرحلة التعرف ونطق الكلمات إلى

$$
\text { مرحلة الفهم الواعي للمقروء }
$$

إن الأصل في القراءة أن تكون للفهم ، لأن الفهم القرائي مهارة رئيسة ، بل هي المهارة المحورية التي يهُف تعليم القراءة إلى تنميتها ، ويحتاج المره القراءة ليس فقط لفهم

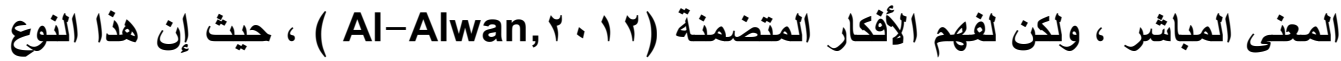
من الفهم هو أحد الأسباب الرئيسة للقراءة " إذ أن القارئ الذى يقرأ بدون فهم للمعنى ،

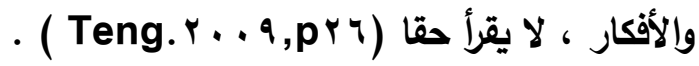

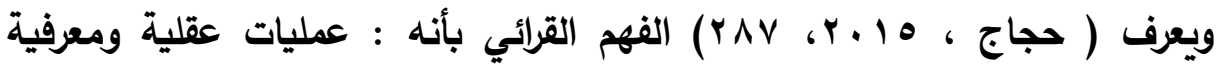
متكاملة ، تصل بالقارئ إلى المعاني التي يحتويها النص مع الاعتماد على خبراته السابقة ، يقوم فيها بالربط بين الكلمات والجمل ثم الفقرات ثم يقوم بالتفسير والتحليل والنقد والتقويم فيبدأ بذلك من مستوى الفهم الحرف إلى مستوى الفهم الإبداعي ، حتى يتمكن من التفاعل باليط بالئ

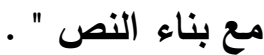

وتعد عملية الفهم القرائي عملية بناء وفهم للمعنى من خلال النصوص ، ويتضمن ذلك إدرالك المعنى الضمني والصريح من النص ، وفهم العلاقات والأفكار داخل النص ، فهي

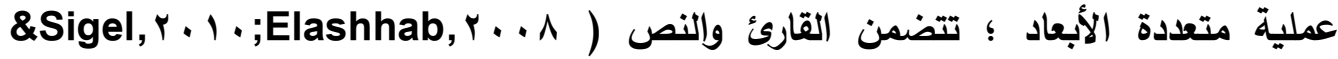

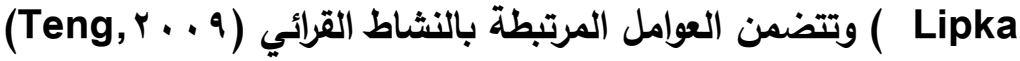
وقد شهدت الساحة التربوية العديد من الدراسات التي تناولت الاهتمام بمهارات الفهم

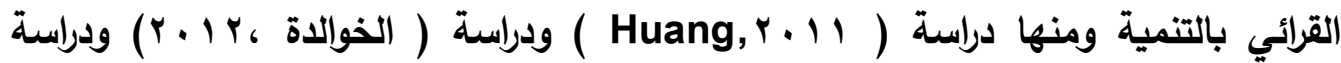
( Spruce, r . I r) المعاني السطحية إلى المستويات الضمنية والنقدية والتذوقية والإبداعية للنص المقروء . وقد نادت بعض الاراسات بضرورة تنمية مهارات الفهم القرائي والتي تسهم في رفع

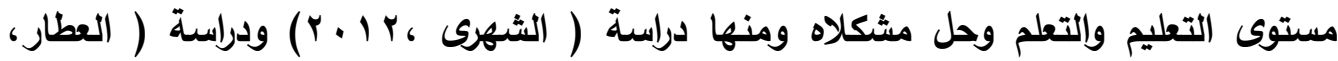




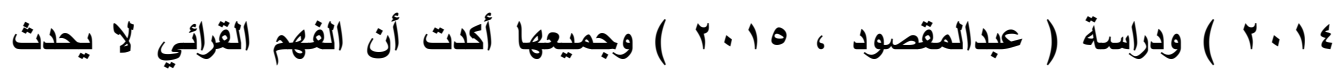
للمتعلم دفعة واحدة فهو يمر بمراحل عديدة بداية من قراءة السطور ،مرورا بإدراك ما بين

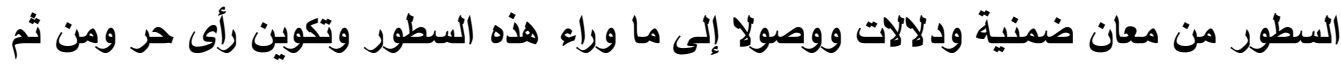

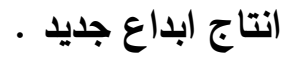

ولم تتخلف وزارة التربية والتعليم عن الركب ولم تكن بعيده عن مشهد تطوير التعليم

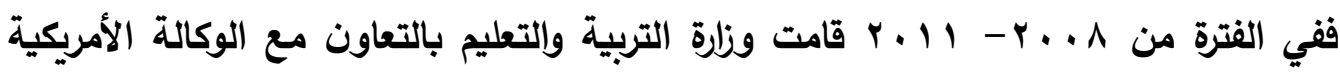
للتنمية الدولية ومن خلال اتفاقية (القراءة للجميع EFA ) و مشئ (مشروع تحسين الأداء التعليمي للبنات Gilo ) على توفير التعليم الإلزامي بالمرحلة الابتدائية للجميع ، ورفع كفاءة

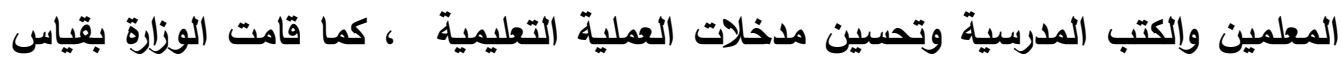
مهارات القراءة للصفوف الأولى وأظهرت النتائج أن ثلثي العينة لم يستطيعوا قراءة كلمة واحدة في فقرة نصية بسيطة ـ واستطاعت نسبة ؟\% تحقيق مؤشر الطلاقة لمعدل هـ كلمة في الدقيقة ، ومن ثم أصدرت الوزارة قررا بأن تكون الطريقة الصوتية طريقة إلزامية في تعليم

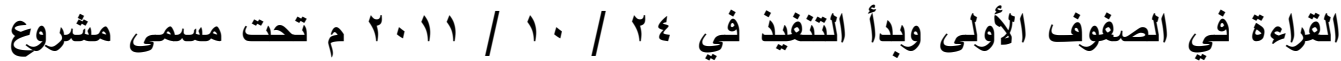

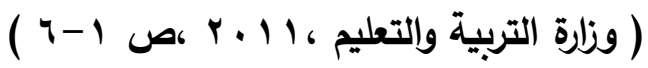
القرائية . وتتماشى رؤية وزارة التربية والتعليم المتمثلة في مشروع القرائية مع اهتمامات الجمعية الدولية للتحصيل التربوي والتي عملت على تطبيق دراسة لقياس مدى تقدم شباب العالم في التنور القرائي وجاء تحت مسمى PIRLS وتثتمل الدراسة على اختبار عالمي يتم

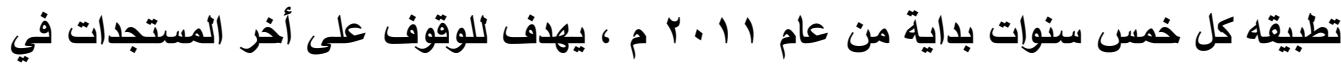
تطوير مهارات الفهم القرائي وتحديد جوانب الضعف والقوة والفروق البينية بين الذكو والإناث، وتوفير قاعدة بيانات عن قدرات التلاميذ القرائية ومدى تقدمه وذلك للمقارنة بين مستويات

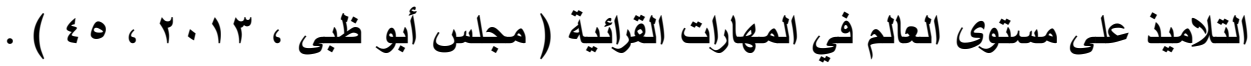

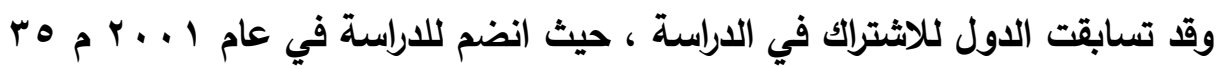

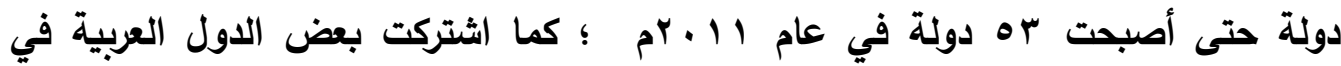

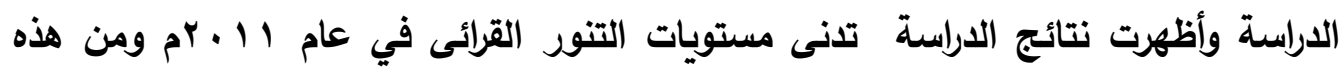
الدول ( عمان - الأمارات - قطر - السعودية ) وكانت من أهم أسباب التدني في النتائج 
الضعف في القراءة والكتابة وضعف فاعلية البرامج المقدمة للمعلمين لتنمية مهارات الفهم

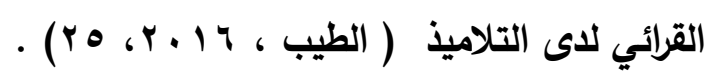

ويحتوى اختبار التنور القرائي على نصوص عامة ليست غرضها قياس التحصيل ولا

ترتبط بمقرر معين أو بنص مألوف ولكن هو إجراء للكثف عن مدى توافر مهارات التنور عارئ

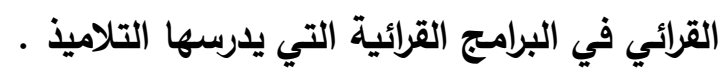
وقد أجرت الباحثة استطلاع رأى لعينة من معلمين اللغة العربية لمرحلة الثانوية التجارية من هدف إلى معرفة مدى احتواء كتاب اللغة العربية لمهارات الفهم القرائي من خلال وجهة نظرهن وتضمن الاستطلاع \& ا فقرة تدور حول مدى تنمية محتوى كتاب اللغة العربية

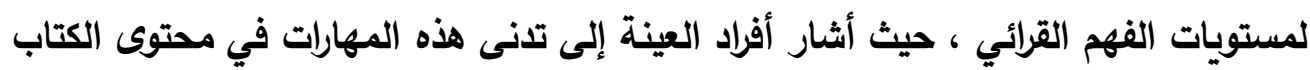
وتأسيسا على ما سبق تنامى للباحثة فكرة البحث الحالي متمثلة في السؤال التالي : ما مدى تضمين محتوى البرنامج القرائي في كتاب اللغة العربية على مهارات الفهح القرائي

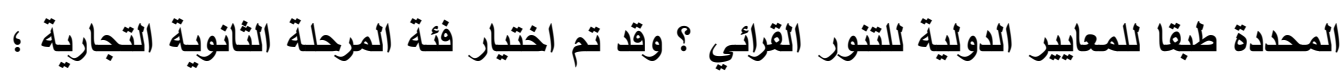
بسبب قيام الوزارة كل عام قبل بداية الدراسة لطلاب الصف الأول بتحديد المهارات اللغوية لايهم من خلال تطبيق اختبار تحديد مستوى ومن ثم تقوم الوزارة بحصر البيانات من أجل

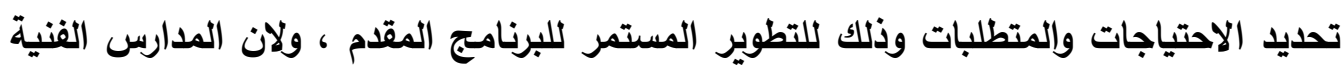

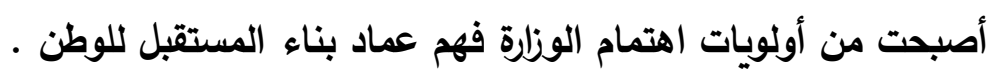

مشكالة البحث حاول البحث الحالي الإجابة عن السؤال الرئيس التالي : كيف يمكن تقويم مهارات الفهم القرائي في البرنامج القرائى لكتاب اللغة العربية بالصف الأول

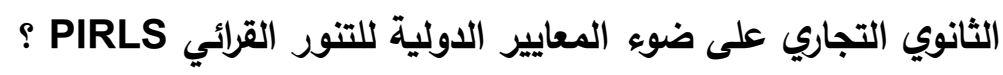
وهذا السؤال يتفرع منه الأسئلة الفرعية التالية : 1 - ما مهارات الفهم القرائي اللازمة للبرنامج القرائى للمرحلة الثانوية على ضوعه المعائه المايير الاولية للتنورالقرائي؟ ץ - ما درجة توافر مهارات الفهم القرائي ضوء المعايير الدولية للتنور القرائي في كتاب اللغة العربية للصف الأول الثانوي التجاري بمستوى استرجاع المعلومات؟ 
r- ما درجة توافر مهارات الفهم القرائي ضوء المعايير الدولية للتنور القرائي في كتاب

اللغة العربية للصف الأول الثانوي التجاري بمستوى تكوين الاستدلالات؟

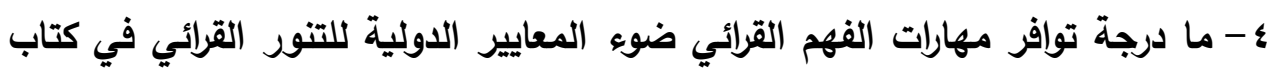
اللغة العربية للصف الأول الثانوي التجاري بمستوى دمج الأفكار وتفسير المعلومات؟ ماته ه - ما درجة توافر مهارات الفهر القرائي ضوء المعايير الدولية للتنور القرائي في كتاب اللغة العربية للصف الأول الثانوي التجاري بمستوى تقويم المحتوى واللغة والعناصر؟ צ- ما المخطط التوصيفى المقترح لتنمية مهارات الفهم القرائي في ضوء المعايير الدولية للتنور القرائي بكتاب اللغة العربية لطلاب الصف الأول الثانوي التجاري ؟أهد|ف البحث

$$
\text { يهدف البحث الحالي إلى البح }
$$

- تحديد مهارات الفهم القرائي الواجب توافرها لطلاب الصف الأول الثانوي التجاري

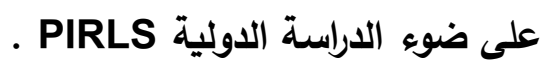
- الكشف عن مدى تضميم مهارات الفهم القرائي للبرنامج القرائى في كتاب اللغة العربية ( استرجاع المعلومات - دمج الأفكار وتفسير المعلومات - تكوين الاستدلالات

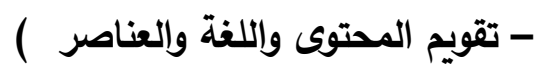
- وضع تصور مقترح لكتاب اللغة العربية لتنمية مهارات الفهم القرائي على ضوء المعايير الدولية PIRLS

أهمية البجث قد يفيد البحث الحالي في : - إلقاء الضوء على مدى تضمين البرنامج القرائى في كتاب اللغة العربية لمهارات الفهم القرائي طبقا للمعايير الدولية للتنور القرائي ، مما يفيد المسئولين عن مناهي

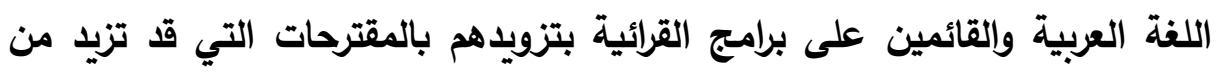
فاعلية البرامج القرائية ومناسبتها للطلاب في حالة اشتراك جمهورية مصر العربية لئه في الدراسة الدولية للتنور القرائي • 
-

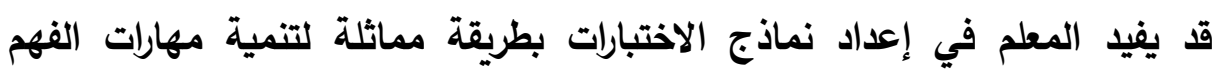
القرائي مدى فاعليتها في التقدم والفهم القرائي .

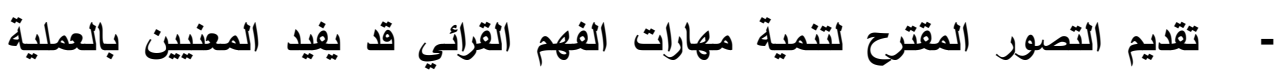
التعليمية بإجراءات تطوير تنمية مهارات الفهر القرائي في ضوء المهرية المعايير الدولية .

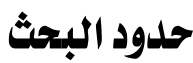

- الحدود المكانية : جمهورية مصر العربية - محافظة بورسعيد

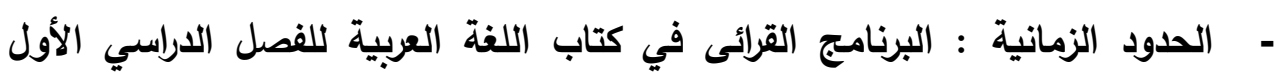

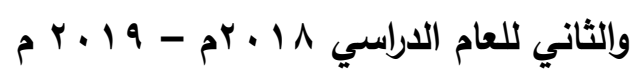

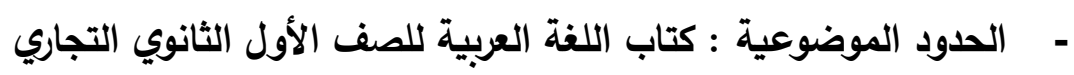

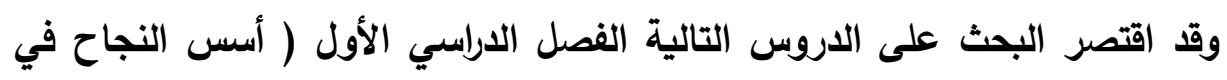

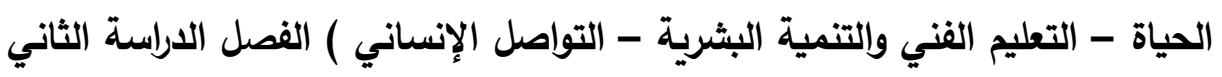

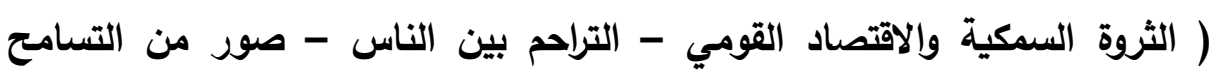

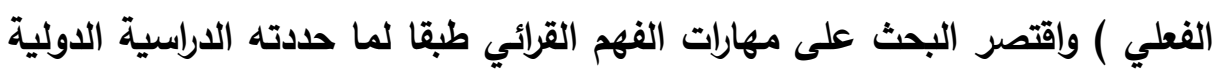

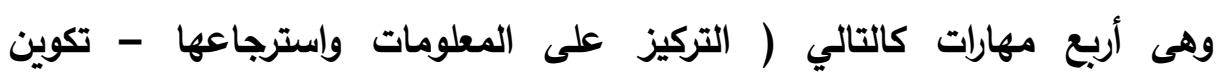
الاستدلات المباشرة - تفسير ودمج الأفكار والمعلومات - تقويم المحتوى وعناصره

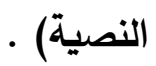

منهج البحث

اعتمد البحث على المنهج الوصفي القائم على تحليل المحتوى ، وذلك لمناسبته

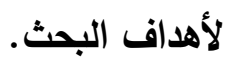


1- قائمة بمهارات الفهم القرائي اللازمة لكتاب اللغة العربية بالصف الأول الثانوي

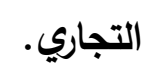

r-بطاقة تحليل محتوى البرنامج القرائى المتضمن في كتاب اللغة العربية للصف

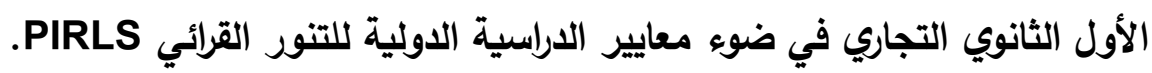

\section{مصطلحات البحث}

$$
\text { الفهم القرائي }
$$

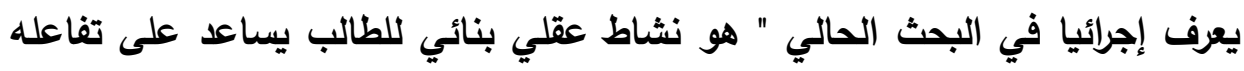

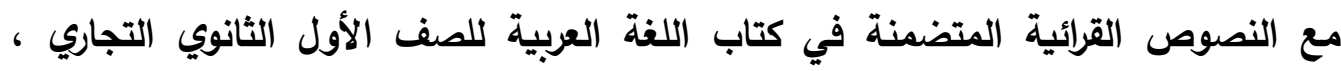
لتكوين المعنى المقصود ضمن المعايير الدولية للتنور القرائى ( التركيز على المعلومات التئية

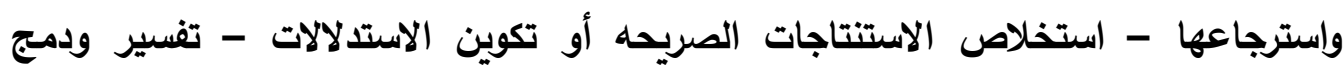

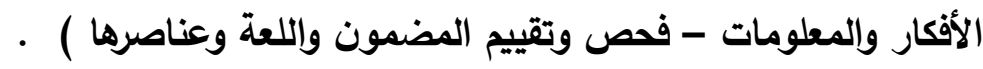
البرنامج القرائى يعرف في البحث الحالي : البرنامج المقدم لطلاب الددارس التجارية بهدف تحسين

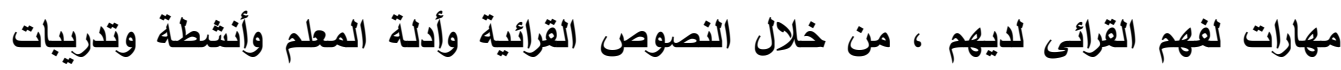

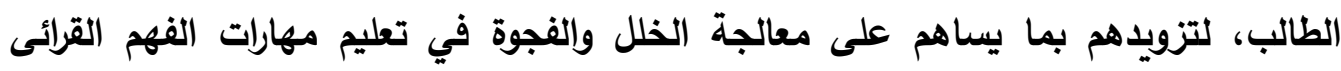
باستراتيجيات وطرق ودعم قومي للوصول إلى مستوى الإبداع . التنور القرائي يعرف في البحث الحالي : بأنه درجة توافر كل مهارة من مهارات التنور القرائي

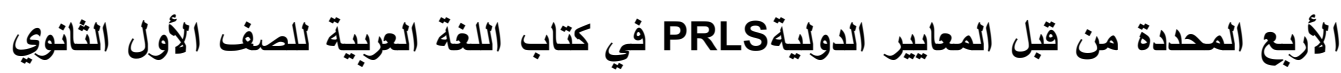
على بطاقة التحليل المصممة لذلك في الكائ الكائ 


\section{الإطار النظري}

المبحث الأول : الفهم القرائي ( مفهومه ، أهميته ، مهاراته ) يعد الفهم القرائي عملية متداخلة تستند على الإدراك العقلي الواعي للفرد ، وما مها مهات

$$
\text { يمتلكه من قدرات ومهارات أساسية للقراءة }
$$

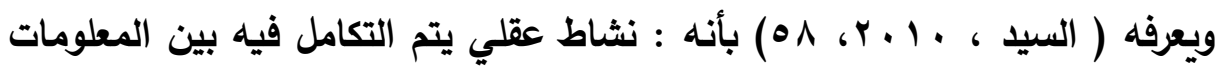

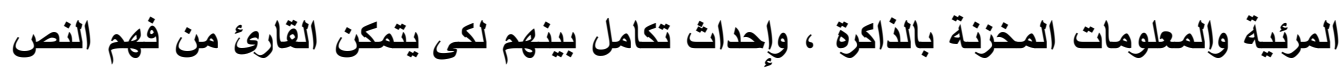
والتفاعل معه ومن ثم تحليله واستخراج المعاني المتضمنة فيه والوصول للفكرة العامة للموضوع ومعرفة غرض واتجاه كاتب النص المقروء .

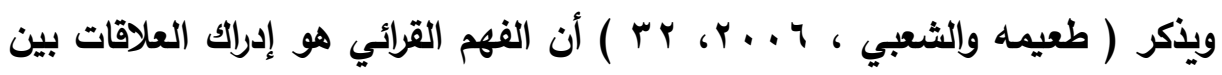

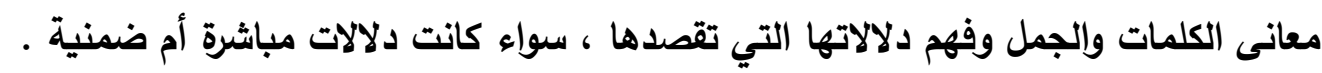

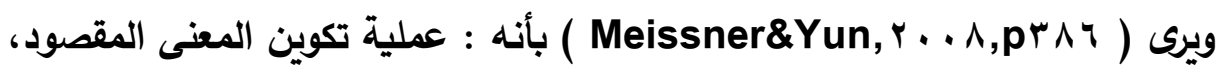
قبل وأثناء وبعد القراءة ، من خلال المزج بين المعلومات التي يستعرضها المؤلف والخلفية المعرفية السابقة في ذاكرة القارئ .

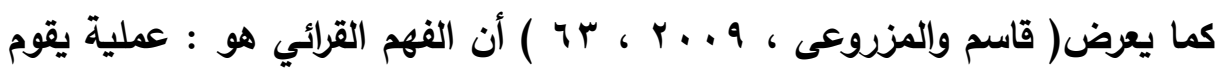

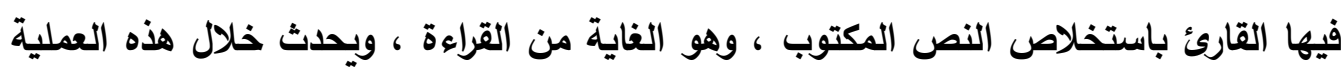

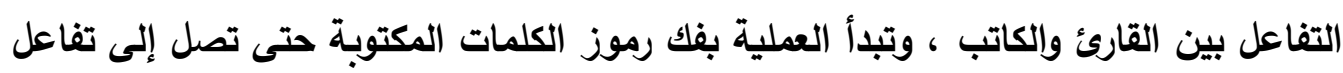
خلفية القارئ المعرفية ، وربطها بالنص للوصول لمغزى الكاتب من النص ل

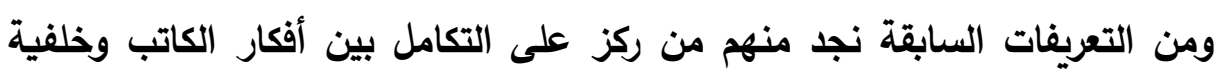

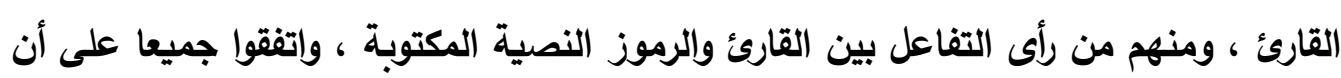

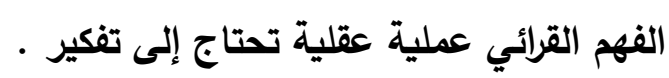
ومما سبق تعرف الباحثة الفهم القرائي بأنه : نشاط عقلي بنائي للطالب يساعد على إلى

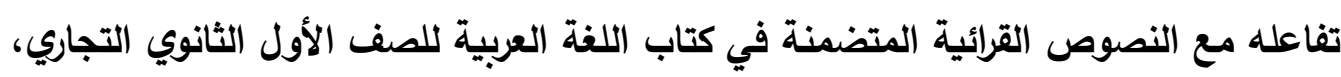
لتكوين المعنى المقصود ضمن المستوى الحرفي والاستنتاجي والناقد والتذوقى . أهمية الفهم القرائي يعد الفهم القرائي أساس عملية القراءة والغاية الرئيسة من القراءة ، وهذا يتطلب تفاعل القارئ مع النص المقروء من شأنه أن يعمل على بناء المعنى المقصود بما يتفق مع 
تقويم مهارات الفهم القرائي في البرنامج القرائي لكتاب اللغة العربية بالصف الأول الثانوي التجاري..............................

طبيعة المعلومات الواردة في النص والخلفية المعرفية وخبراته السابقة للقارئ وإدراكه

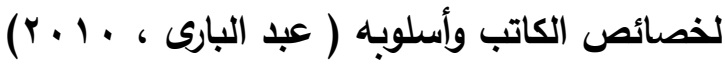

ولكى يحقق التفاعل هدفه يجب أن يكون القارئ قادرا على تحديد الأفكار الرئيسة في الفقرة ، والإلمام بجوانب موضوع النص المكتوب ، وربط الأفكار بالخبرات السابقة ، حتى يزداد القارئ وعيا ونضجا وامتلاك مهارات الدقة والبحث المتسق مع المعنى من النص

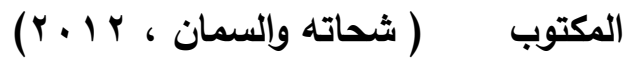

إن القراءة لن تؤتى ثمارها الا إذا اقترنت بالفهم، حيث أن الفهم مطلب مهم للقراءة

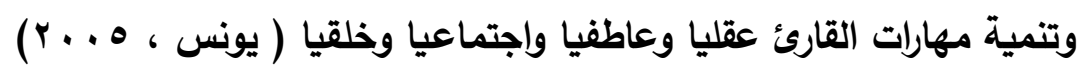
لذلك دعيت الاراسات بضرورة الاهتمام بالفهم القرائي مع تكثيف التدربب على هذه المهارات ليتسنى تحقيق التقدم للتلاميذ في جميع مجالات الدراسة وعلى مدار المراحل

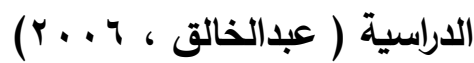

وقد يشار إلى أن الفهم القرائي عملية عقلية ت تتطلب من القارئ تفاعلاً مع النص وربط المعلومات السابقة من أجل التعرف على بنية النص وتراكيبها اللغوية وأساليبها البيانية ومنها تحليل النص واكتشاف ما به من أحكام وقيم المنيم

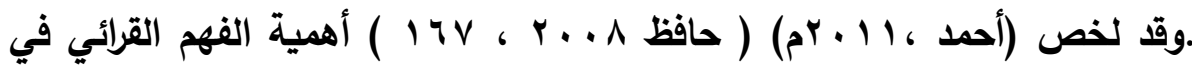
النقاط الآتية :

ا ـالاستفادة القصوى من النص المقروء بأفضل صورة ممكنة .

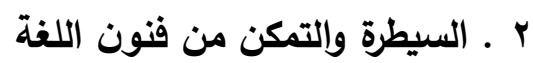

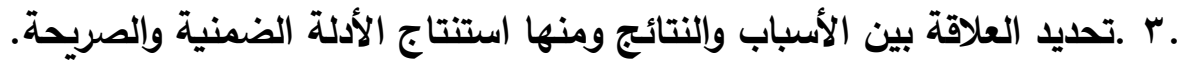
؛ .زيادة التحصيل الدراسي في شتى المجالات المختلفة. ه - الفهم القرائي أساس تعلم كل مقروء . 4. الفهم القرائي يرتقى بلغة المتعلم ويزيل ثروته اللغوية . V. الفهم القرائي يقلل من أخطاء المتعلمين وينظم الأفكار . مهارات ومستويات الفهم القرائي تضمنت مهارات الفهم القرائي العديد من المستويات والمستويات ، وهى غالبا ما تأخذ بعدين ؛ بعدا رأسيا يتناول مستويات الفهم الحرفي ، والضمني وما بين السطور والاستنتاج والنقد 
والتذوق ثم الإبداع ؛ وبعدا أفقيا ويتناول فهم الكلمة ثم الجملة ثم الفقرة واستخراج الأفكار

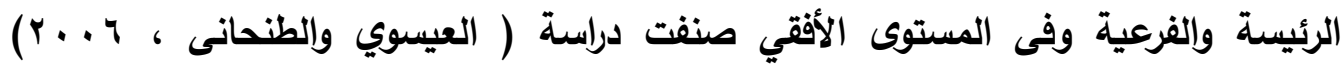
مهارات الفهم إلى :

1 - المهارات على مستوى الكلمة : وتتضمن المرادف والتضاد والمعنى . r- المهارات على مستوى الجملة : وتثثمل فهم المعنى من السياق ، أو عبارة تمها للجمل التي تليها ، أو جمل تلخص الأفكار السابق ورودها . r- المهارات على مستوى الفقرة : وتثمل ترتيب الكاتب للأفكار مع مراعاة التتابع الزماني والمكاني للأحداث في ترتيب الجمل ، تحديد الفكرة الرئيسة للمقروء. ع - المهارات على مستوى النص : وتتضمن فهم جميع مكونات الكلمات وأجزاء الجمل والثقرات ، ثم الربط بينها لتكوين فهم متكامل عن الموضوع . ومن السابق يتضح أن المستوى الأفقي للفهم القرائي يهتم بالثكل والحجم وهذا لا يمكن المعلم من التوصل بطلابه إلى المستويات العليا المنشودة

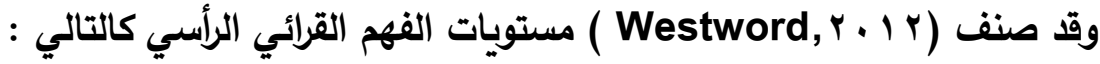
ا- المستوى الحرفي : يتضمن المعلومات الأساسية الواردة تصريحا في النص المقروء . r- المستوى الاستتتاجي : وهنا يتمكن القارئ من فهم ما وراء الكلمات في النص وإنتاج معان جديدة للوصول إلى النهاية المناسبة للموضوع • r- المستوى الناقد : يقوم فيه القارئ النص المكتوب ويحدد فيه من مبالغات واضحة وتحيز ويصدر فيه الحكم على النص لغويا ووظيفيا وفق قواعد ومعايير مناسبة . צ - المستوى الإبداعي : ويستطيع القارئ فهم و تطوير ما ورد في النص للوصول

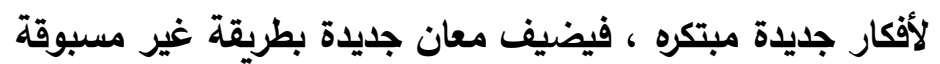
وهناك من الدراسات التي عرضت مستويات ومهارات الفهم القرائي بطريقة أخرى أكثر تفصيلا

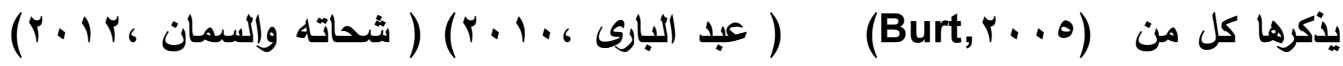

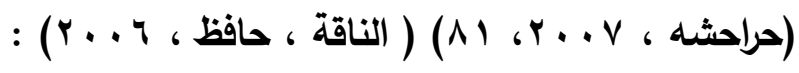
1- مستوى الفهم الحرفي : ويقصد بها الكلمات والجمل والأفكار التي وردت بالنص بطريقة مباشرة وصريحة وتتضمن 
أ- مهارة تطوير الثروة اللغوية : وتتضمن ؛ تحديد المعنى من سياق الجملة ، التعرف على دلالة الكلمة من المعاجم ، تعديد مرادف ومضاد الكلمات . ب-مهارة تحديد تفاصيل النص : وتثمل الوصول إلى الحقائق والمعلومات التي مرلي

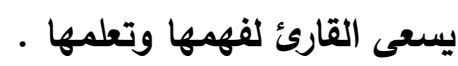
ت-مهارة تحديد الفكرة الرئيسة : وتثمل تحديد القارئ للفكرة الرئيسة التي يتحدث عنها النص من عنوان النص أو من العناوين الفرعية للنص .

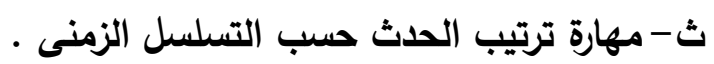
r- مستوى الفهم الاستنتاجي : ويعتمد إلى الوصول لخاتمة منطقية مبنية على خبرة

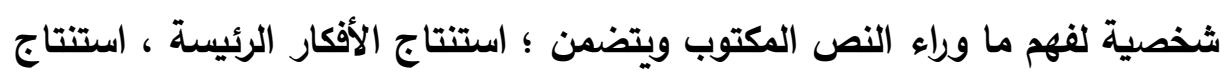
علاقة السبب بالنتيجة ، استنتاج الاتجاهات والقيم من النص ، تلخيص المقروء

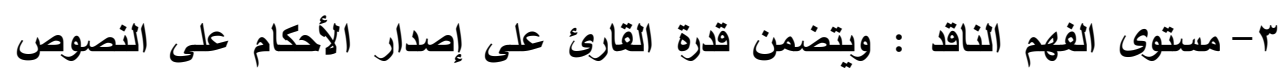
المكتوبة من خلال التحليل والمقارنة والتمييز بين الحقيقة والخيال والرأي والحقيقة والأفكار الرئيسة والفرعية والربط والحكم على تسلسل الأفكار منطقيا .

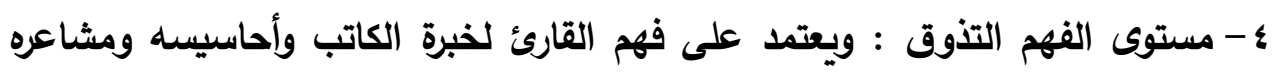

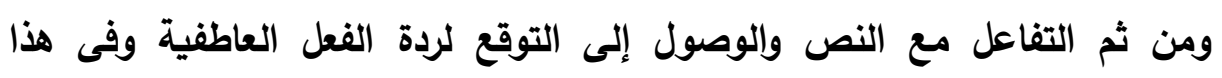
المستوى يمكن للقارئ ؛ تحديد العاطفة الظاهرة والصور البيانية ، وتحديد التعبير الأجمل ، وترتيب الأفكار الواردة في النص ، وتخئ ؛ ولفيل الأحداث ه- مستوى الفهم الإبداعي : ويتمثل في الوصول إلى أفكار جديدة ومسارات فكرية ومعان جديدة للنص واقتراح حلول إبداعية للمشكلات ، وتوقع نهاية النص القرائي بناء على الأحداث فيه . ومستويات الفهم القرائي السابقة لا يمكن الفصل بين عملياتها فكلها متكاملة والدانيا منها تؤدى إلى العليا وتبدأ مستويات الفهم القرائي من العمليات البسيطة ثم تتدرج في التعقيد ويمكن تمثل ذلك في الشكل التالي 
العمليات

الجزئية إنماثة
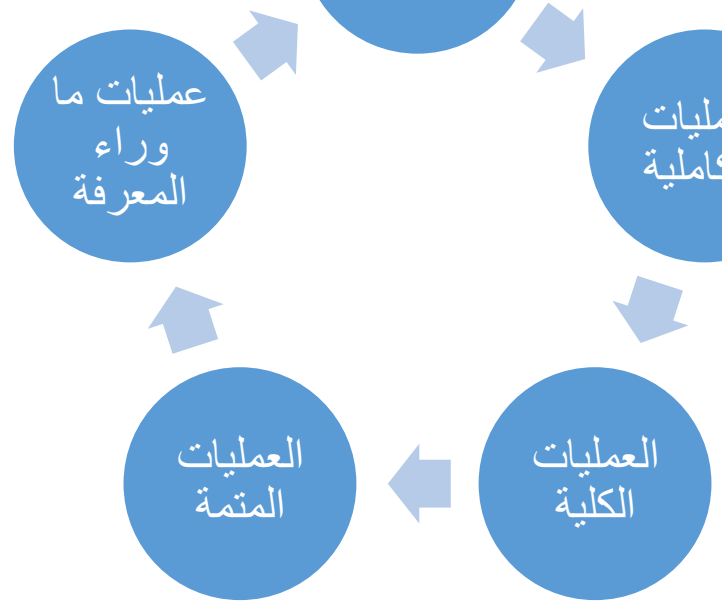

شكل ( 1 ) مراحل تكوين عمليات الفهم القرائي

\section{المبحث الثاني البرنامج القرائي ( المفهوم والأهمية )}

يعتبر امتلاك المهارات القرائية هي أساس كل المعارف البثرية ، التي تساعد على

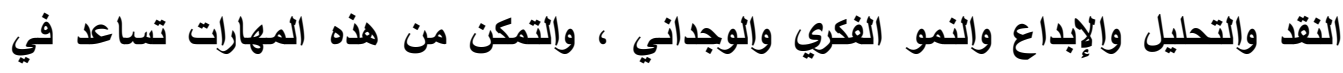
الوصول إلى حل المشكلات واكتشاف الطرق لإبداعية واتخاذ القرارات ، فهي أداة المجتمع والإن نحو التقدم والتغيير الثقافي والاجتماعي والفكري ، وتعمل على تنمية التفكير المنظم ومن ثم تحمل المسئولية والاعتماد الأتي . ظهرت عدة مصطلحات ترتبط وتتداخل مع مفهوم القرائية مع اختلاف أو اشتراك الخصائص والصفات ويمكن عرضها كالتالي :

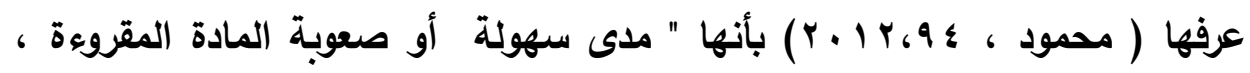
ويمكن قياسها بمستوى فهم القارئ وتتعلق بطول الكلمات والجمل ، ويكون لها مقاييس معده

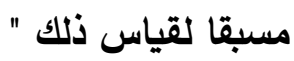

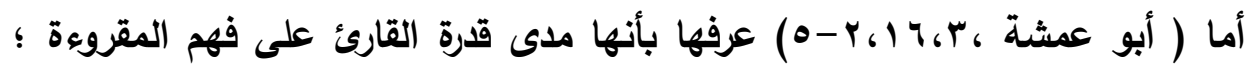
نظرا لسهولة اللغة المستخدمة وتوافقها مع الميول القرائية " وهذا التعرف جاء بمعنى الانقرائية 
وتارة أخرى يرى : أنها دراسة العوامل المؤثرة في درجة قراءة النص المطبوع ومنها حجم الحرف وشكله وطول الجمل ونوع الورق وطريقة طباعته المستخدمة " وهنا جاء التعريف بمعنى البحوث المقروية .

ويمكن استخلاص تعريف البرنامج القرائي بأنه : برنامج يهذف إلى تحسين مهارات القراءة لاى طلاب المدارس التجارية ، من خلال البرامج التدربية وأدلة المعلم ، من أجل باله تزويدهم بما يساهم على معالجة الخلل والفجوة في تعليم المهارات القرائية باستراتيجيات وطرق ودعم قومي للوصول إلى مستوى الإبداع .

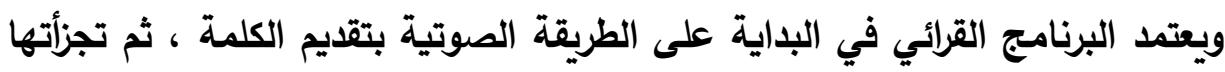
الى مقاطع صوتية ثم حروف ، ثم ينتقل البرنامج من مرحلة التعرف على الأصوات إلى مرحلة التعرف على المفردات وهى تمثل الكلمات التي يجب أن يعرفها الطالب ويستخدمها إما شفويا في التحدث او التعرف عليها سمعيا ، أو فرائيا ، وتلعب المفردات دورا مهما في تعلم القراءة فالقارئ المبتدأ يستخدم الكلمات التي يسمعها ليفهم الكلمات التي يراها مكتوبة ، وبعد اتقان الربط بين الأصوات والحروف والتمييز الصوتي يصبح القارئ قادرا على قراءة المفردات ويتقدم بنجاح في البرنامج القرائي وينتقل الى مراحل الطلاقة وقراءة النص بدقة وسرعة ثم القراءة

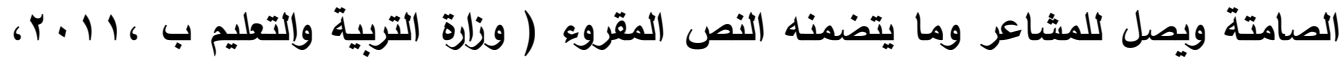
9). ويمكن ايجاز مراحل التقدم في البرنامج القرائي في الثكل التالي :

الأصوات الطلاقة

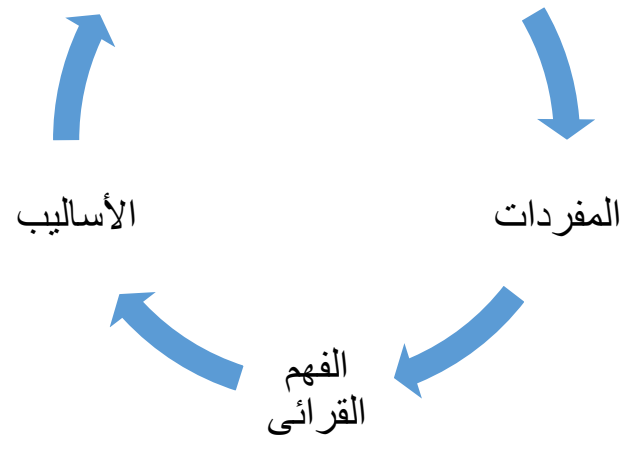

شكل ( r ) مراحل تنمية المهارات القرائية ضمن البرنامج القرائى 
المبحث الثالث : التنور القرائي والدراسة الدولية

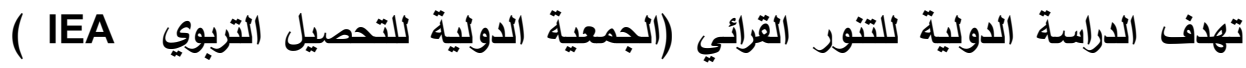

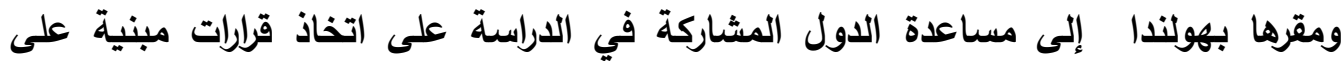
معلومات وبيانات دقيقة حول تحسين التعليم والبرامج القرائية المقدمة ويكمن أهمية الاراسة للدول المشاركة في مقارنة مستوى طلابها في القراءة بالمستوى العالم والوقوف عن قرب على جميع التغيرات التي تؤثر في نتائج الاختبار الدولى ، مما يعكس حقيقة مستوى التلاميذ في البرنامج القرائي ومن ثم يساعد المعنيين بالعملية التعليمية باتخاذ القرارات المناسبة لرفع كفاءة الطلاب القرائية . تهتم الدراسة الدولية للتنور القرائي PIRLS بقياس مهارات فهم المقروء بلغة

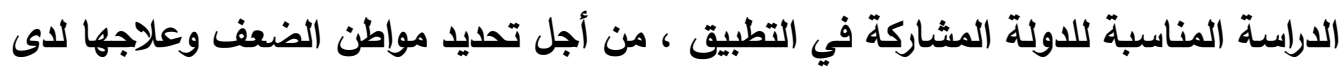
التلاميذ وتعزيز مواطن القوة ، والمساعدة في التخطيط الجيد لرفع كفاءة ومهارات القارئ .

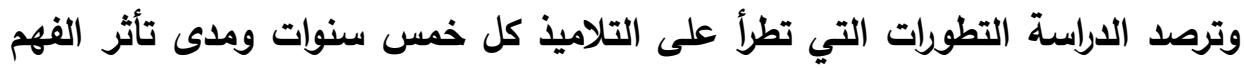

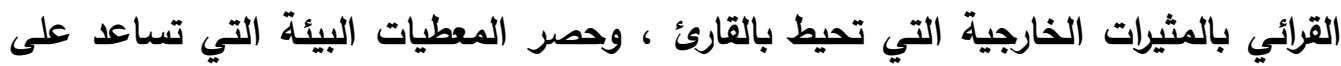

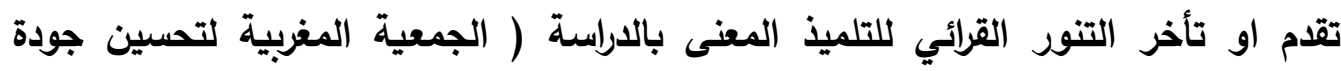

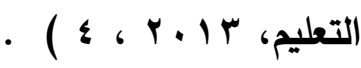

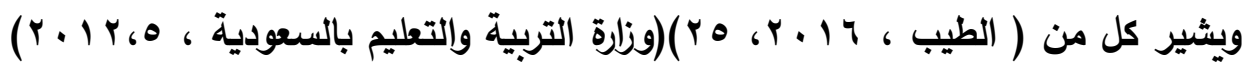

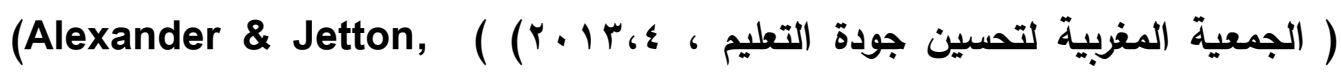

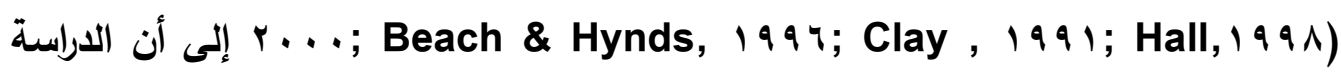
الدولية تعتمد على أربع مهارات للفهم القرائي وهى :

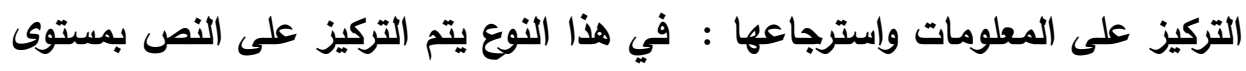

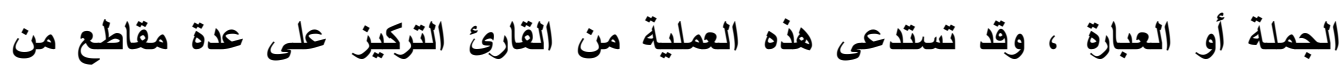

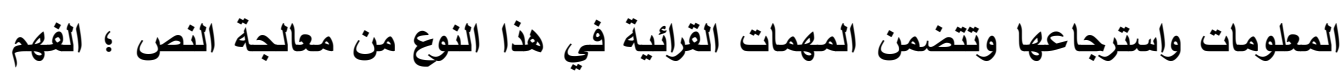

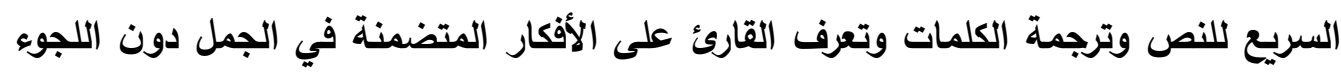

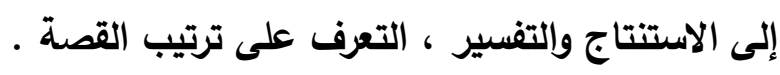

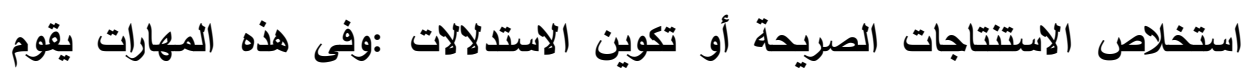

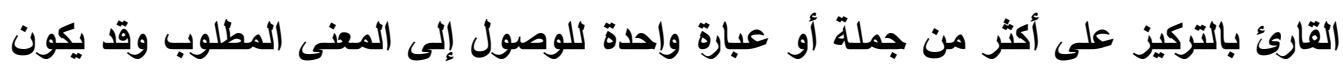


التركيز على معنى موضعى يقع في جزء من أجزاء النص أو التركيز على المعنى الثامل المتمثل في النص بأكمله وتثمل مهمات القراءة في هذه المهات المهارات ( الربط بين الأفكار والمعلومات الواردة في النص مع بعض الاستنتاجات المباشرة والتركيز على فترة زمنية وربط

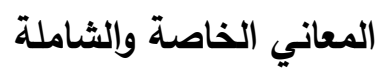

تفسير الأفكار ودمجها : ويحتاج القارئ هنا إلى الاعتماد على فهم العالم وبناء علاقات ليست مفهومه ضمنا ولكن تعتمد على وجهه نظرهم الخاصة لكى يقوم القراء بتفسير ودمج المعلومات والأفكار فقد يحتاجون إلى معلومات وتجارب مسبقة لتفسير الأفكار وتثمل تلفيل مهمات القراءة هنا (فهم ما ما وراء السطر مع الثرح والتعليل واستخلاص النتائج ومعالجة النص المقروء - المقارنة بين معلومات النص - الاستدلال على جو النص - تدديد التصرفات البديلة للثخصيات وتفسير التطبيق الحقيقي والواقعي للمبلومات ). تقويم المحتوى ولغته وعناصره : وهنا يستخدم القارئ إلمامه في استعمالات اللغة

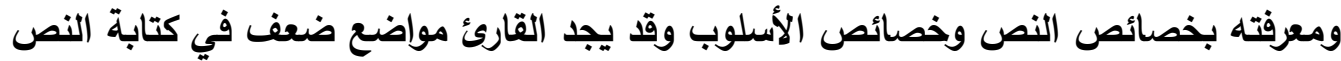
أو يلاحظ البراعة في الكتابة ويتضمن ذلك التعامل مع النص المكتوب كأداة لنقل المعلومات

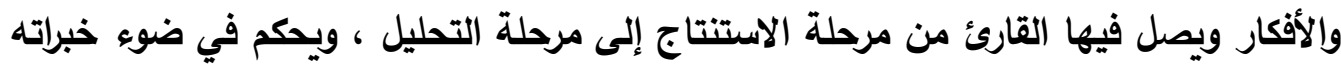

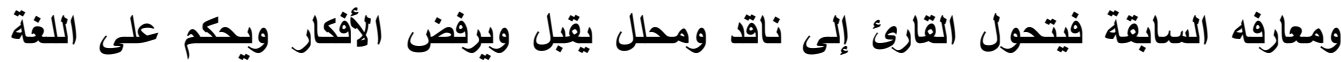

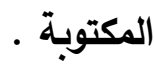
إن أداء التلاميذ ذوى الأداء المرتفع في الدراسة الدولية يكونون قادرين على فهم

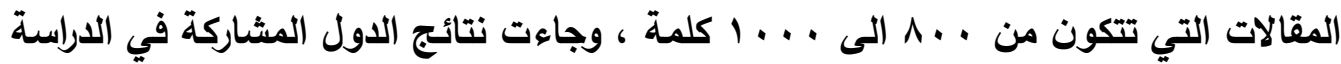
بالترتيب التالي؛ : هونج كونغ ، روسيا ، فلندا ، سنغافورة ، ايرلندا الثمالية ، الولايات

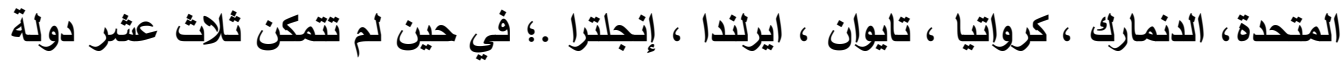
من بين خمس وأربعين دولة الوصول الى المتوسط المطلوب دوليا ـ . ـ كلمة .

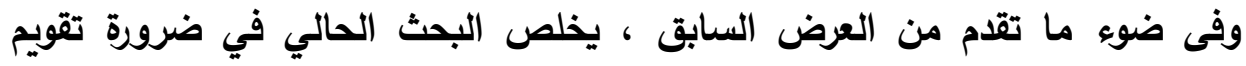

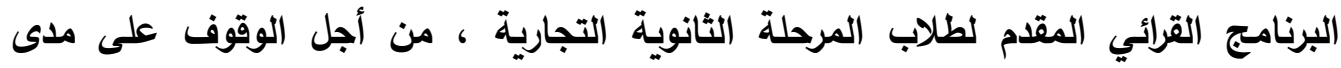
تضمينه لمهارات التنور القرائي التي حددتها الداسة الدولية من أجل رفع كفاءة الطالب التابل القارئ ومن ثم تقديم مقترح تخطيطي لتضمين مهارات الفهم القرائي في ضوء معايير التنور التهائ القرائي للاراسة الدولية 
بناء أدوات البحث وإجراءاته

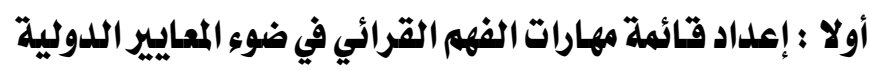

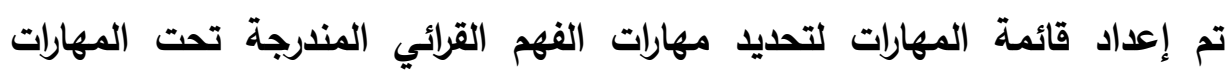

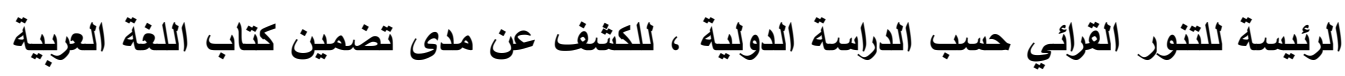

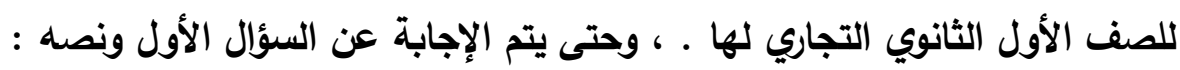

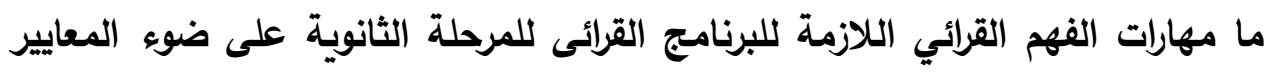
الدولية للتنور القرائي؟

وقد سارت إعداد القائمة بالذطوات التالية : 1- تحديد الهلف : هدفت القائمة إلى تحديد مهارات الفهم القرائى اللازمة لطلاب الصف الصفال

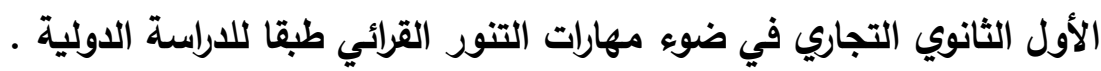
r- مصادر القائمة : تم الرجوع إلى عدة مصادر لبناء القائمة ، بهذف تحديد المهارات وذلك الكائ

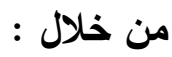

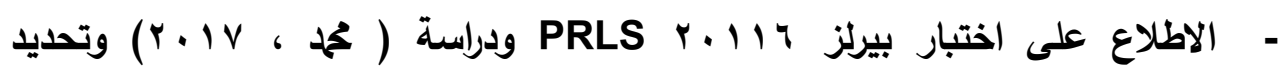

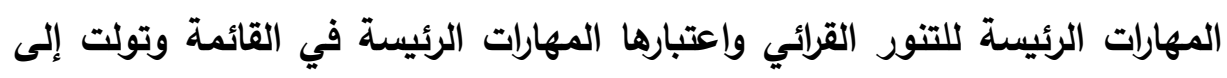

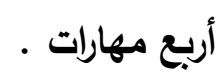
- الاطلاع على الدراسات التي استخدمت الفهم القرائي بالتنمية أو التحليل للتوصل إلى

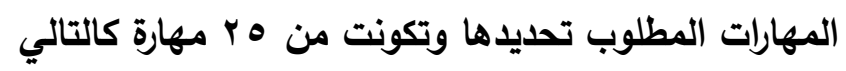
أ- مهارات مهارة استرجاع المعلومات واشتملت على 1 و مهارات ب-مهارات تكوين الاستدلالات واشتملت على 1 مهارات

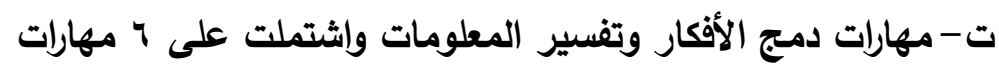

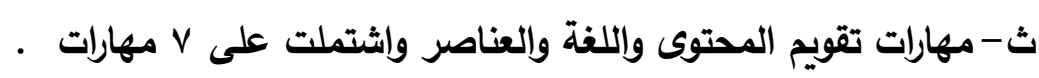

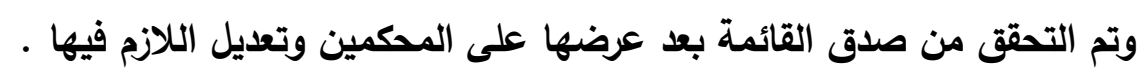

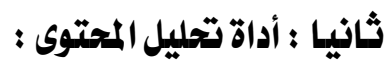
• الهذف من بطاقة التحليل : تهاف البطاقة إلى تحليل كتاب اللغة العربية لطلاب الصف

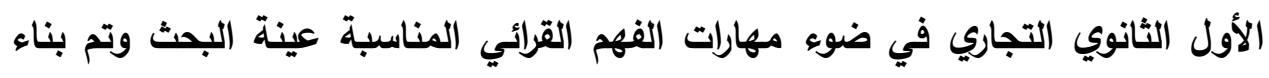

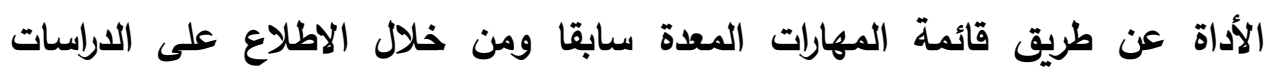


السابقة، وتضمن المحور الأفقي في البطاقة الوحدة ، الدرس ، ورقم الصفحة ، وتضمن

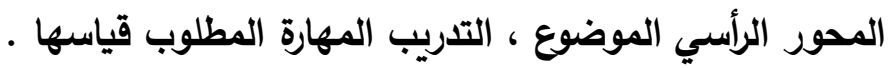

تقتضى تحليل المحتوى تحليل محتوى دروس الكتاب والتدريبات التابعة لكل درس ، ووصف عناصرها وصفا كميا ؛ فقد تم تحديد فئة التحليل ، ووحدته عن طريق

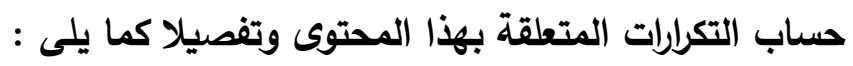
أ- إجراءات التحليل : تم تحديد دروس الوحدات القراءة للصف الدراسي الأول والثاني من كتاب الطالبة كوحدات لتحليل المحتوى .

ب- فئات التحليل : تم تحديد كل مهارة من مهارات الفهم القرائي الواردة في القائمة. ت-وحدة التحليل : تم الاعتماد على وحدة السياق ( الجملة ) في تحليل محتوى وحدات البرنامج القرائي ، وقد اعتبرت الباحثة في التدرببات ؛ التدريب الواحد

\section{وحدة سياق}

ث-تم رصد التكرارات لكل مهارات في الدروس المحددة ؛ الفصل الدراسي الأول ( أسس النجاح في الحياة - التعليم الفني والتنمية البثرية - التواصل الإنساني ) الفصل الدراسة الثاني ( الثروة السمكية والاقتصاد القومي - التراحم بين الناس - صور من التسامح الفعلي ) ثم كررت نفس العملية بعد مرور أسبوعين من التحليل وحساب معامل الاتفاق بين المرتين .

حساب ثبات التحليل

تم حساب ثبات التحليل من خلال معامل الاتفاق للتحليل بمعادلة هولستى بين المرتين ، للتحقق من موضوعية التحليل وجاءت معامل الثبات ؟9\% وهو معامل ثبات عال يدل على ثبات التحليل والجدول التالي يحد ذلك ملك جلول (1)

ثبات التحليل لكتاب الطالبة فى اللغة العربية للصف الأول الثانوي التجاري

\begin{tabular}{|c|c|c|c|c|}
\hline معامل الثبات & المجموع & نقاط الاختلاف & نقاط الاتفاق & مستوى الفهم القرائي \\
\hline$\% 9$ & VI & $\mathrm{V}$ & $7 \varepsilon$ & مهارة استرجاع المطلومات \\
\hline$\% 1 \ldots$ & $r \cdot$ & . & $r \cdot$ & تكوين الاستدلالات \\
\hline$\% 1 \ldots$ & $1 \leqslant$ & - & $1 \leqslant$ & دمج الأفكار وتفسير \\
\hline$\% 1 \ldots$ & $\varepsilon$ & - & $\varepsilon$ & تقويم المحتوى واللغة \\
\hline$\% 9 \varepsilon .1$ & & & & المجموع \\
\hline
\end{tabular}


- اشتملت بطاقة التحليل البرنامج القرائي المقدمة لطلاب الصف الأول الثانوي وهو يتضمن الوحدة الأولى في الفصل الاراسي الأول والوحدة الأولى في الفصل الدراسي

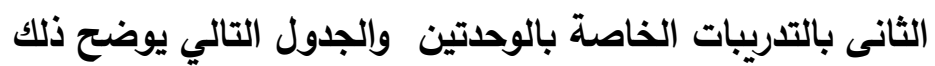

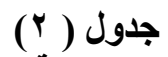

\begin{tabular}{|c|c|c|}
\hline عدالد الأنشية والمستثدفة والتيبات & عنوان الدرس المستهـف & الوحدة \\
\hline 10 & أسس النجاح في الحياة & \multirow{3}{*}{ الفصل الدراسي الأولى الألى } \\
\hline 17 & التعليم الفني والتنمية & \\
\hline 11 & التواصل الإنساني & \\
\hline 17 & الثروة السمكية والاقتصاد & \multirow[t]{3}{*}{ الفصل الاراسي الثاني } \\
\hline 11 & التراحم بين الناس & \\
\hline 10 & صور التسامح الفعلي & \\
\hline ع ـ تدريبا & 7 دروس & المجموع \\
\hline
\end{tabular}

\section{تحليل النتائج وتفسيرهـا}

\section{لـإجابة على السؤال الأول ونصه}

- ما مهارات الفهم القرائي اللازمة للبرنامج القرائى للمرحلة الثانوية على ضوء المعايير

$$
\text { الدولية للتنور القرائي؟ }
$$

تم التوصل إلى قائمة مهارات الفهم القرائي اللازمة لطلاب الصف الأول الثانوي التجاري في ضوء معايير الدراسية للتنور القرائي وكان عدد المهارات الرئيسة أربع

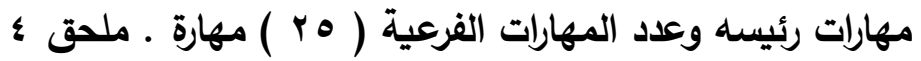
لإإجابة عن السؤال الثاني ونصه : ما درجة توافر مهارات الفهم القرائي ضوء المعايير الدولية للتنور القرائي في كتاب اللغة العربية للصف الأول الثانوي التجاري بمستوى استرجاع المعلومات؟ للإجابة عن السؤال تم حساب نسب التكرارات للتحقق من مدى توافر مهارات مستوى استرجاع المعلومات وكانت النتائج كالتالي 
تقويم مهارات الفهم القرائي في البرنامج القرائي لكتاب اللغة العربية بالصف الأول الثانوي التجاري.

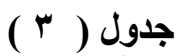

التكرارات والنسب المئوية لمهارات استرجاع المات المعلومات

\begin{tabular}{|c|c|c|c|c|c|c|c|c|}
\hline الترتيب & النسب & التكرارات & المئوية & التكرار التبب التشبة & المئوينة & التكرار & الفرعهة من المهارة & r \\
\hline 7 & $\% 0,7$ & 1. & $\% 7.7$ & $\varepsilon$ & $\% 0.1$ & 7 & للنصئيسة & 1 \\
\hline$\varepsilon$ & $\% \mid 1 . r$ & $r$. & $\% r . r$ & $r$ & $\% 10.0$ & 11 & اللتحاصيل & $r$ \\
\hline 1 & $\% \leqslant \wedge, \wedge$ & $\wedge 7$ & $\% \leq 7.7$ & $r \wedge$ & $\% 0^{0}$ & $\Delta \wedge$ & تحديد أفكار & $r$ \\
\hline 0 & $\% \vee, q$ & $1 \leq$ & $\% 1$ & 7 & $\%$ & $\Lambda$ & ادراك ترتيب الأكرات & $\varepsilon$ \\
\hline$r$ & $\%{ }^{\prime}{ }^{\prime}, 0$ & $r r$ & $\% 17.7$ & 1. & $\% 1 \cdot . r$ & Ir & المداسل معنى الكبلم من & 0 \\
\hline$r$ & $\% \backslash r, r$ & $r \varepsilon$ & $\%$ & 1. & $\% \backslash r$ & $1 \varepsilon$ & تحديل مضاد & 7 \\
\hline \multicolumn{2}{|c|}{$\% 1 \ldots$} & 187 & $\% 1 \ldots$ & 7. & $\% 1 \ldots$ & 117 & \multicolumn{2}{|l|}{ المجموع } \\
\hline
\end{tabular}

يبين جدول ( r) التكرارات واللنسب المئوية والترتيب لمهارات مستوى استرجاع المعلومات ، ويتضح من الجدول أن المهارات قد وردت في كتاب اللغة العربية للصف

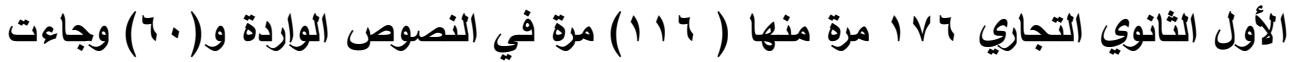
المهارة الأولى تحديد أفكار معينة في النص بنسبة ^ ^؛\% وتليها مهارة تحديا مضاد الكلمة بنسبة r,r\% \% ثم المهارة الثالثة مهارة تحديد معنى الكلمة المناسب بنسبة

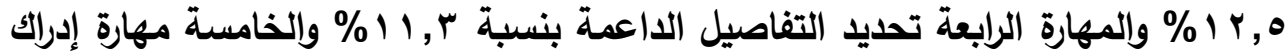
ترتيب الفقرات بنسبة 9.\% و والمهارة الأخيرة بنسبة تحديد الفكرة الرئيسة في النص بنسبة 
تقويم مهارات الفهم القرائي في البرنامج القرائي لكتاب اللغة العربية بالصف الأول الثانوي التجاري.

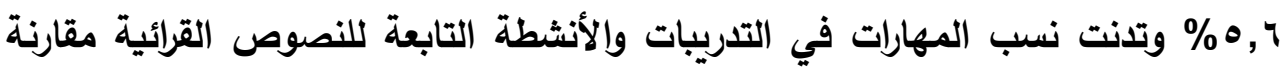
بنسب التكرار في النص وتباينت التكرارات في القياس ، وقد تعزى هذه النتيجة إلى غياب منهجية واضحة في إعداد تدريبات النصوص القرائية وتنوعها ويتفق مع هذه النتيجة

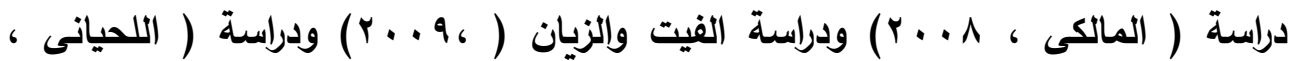

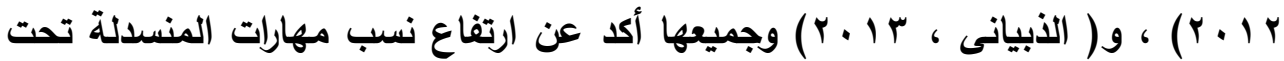
مسمى الفهم الحرفى في النصوص الواردة عنها في التدريبات والأنثطة وللإجابة عز السؤال الثالث ونصه : - ما درجة توافر مهارات الفهم القرائي ضوء المعايير الدولية للتنور القرائي في كتاب اللفة العربية للصف الأول الثانوي التجاري بمستوى تكوين الاستدلالات؟ للإجابة عن السؤال تم حساب نسب التكرارات والنسب المئوية للتكرارات في النصوص القرائية والتدرببات والأنشطة والجدول التالى يوضح ذلك .

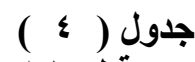

التكرارات و النسب المئوية لمهارات تكوين الاستدلالات

\begin{tabular}{|c|c|c|c|c|c|c|c|c|}
\hline الترتيب & النسب & التكرارات & المئوية & التكرار & المئوية & التكرار & الفرعية من المهارات & p \\
\hline$r$ & $\% 17.9$ & 9 & $\% 0^{0} . Y$ & 1 & $\%$ rr,o & $\wedge$ & 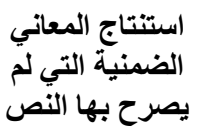 & 1 \\
\hline$\varepsilon$ & $\% 10$ & $\wedge$ & $\% 1 \cdot, 0$ & $r$ & $\% \backslash \vee, 7$ & 7 & مناسبة للانص نهاية & r \\
\hline 1 & $\%$ & Ir & $\% 1 \cdot .0$ & 7 & $\% \backslash \vee, 7$ & 7 & التتيتاج الأقكار & $r$ \\
\hline r & $\% \backslash V . r$ & 1. & $\%$ Y & $\varepsilon$ & $\% \mid \vee, 7$ & 7 & بالمبط المعلومات & $\varepsilon$ \\
\hline 0 & $\%$ \% Y.V & $\wedge$ & $\%$ Y & $\varepsilon$ & $\% \backslash 1, \vee$ & $\varepsilon$ & علاقات الستبتاج & 0 \\
\hline 7 & $\%$ & 7 & $\% 1 \cdot .0$ & $r$ & $\% \backslash 1 . V$ & $\varepsilon$ & بين الشف العلاقة & 7 \\
\hline
\end{tabular}




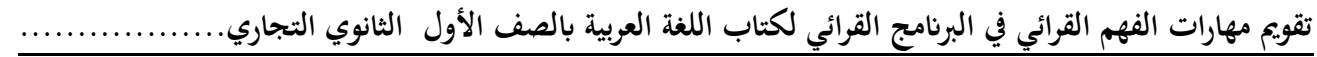

\begin{tabular}{|c|c|c|c|c|c|}
\hline$\% 1 \ldots$ & or & $\% 1 \ldots$ & 19 & $\% 1 \ldots$ & $r \varepsilon$ \\
\hline
\end{tabular}

يتبين من الجدول ( \& ) تكرارات ونسب ترتيب مهارات مستوى تكوين الاستدلالات كما

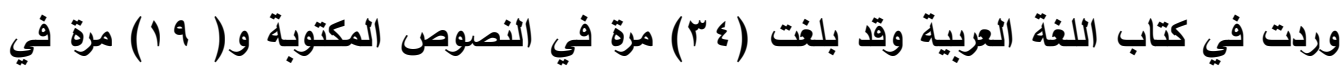

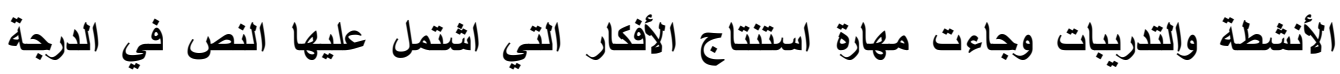

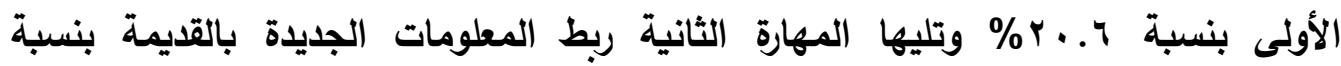

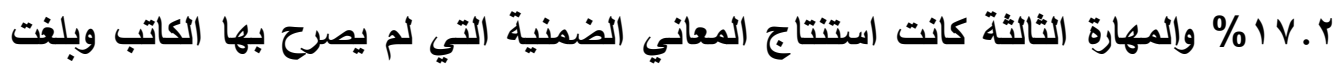

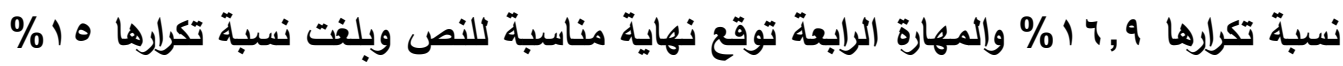
والمهارة الخامسة علاقة السبب بالنتيجة وبلغت نسبة تكرراها V, VI\%والمهارة السادسة

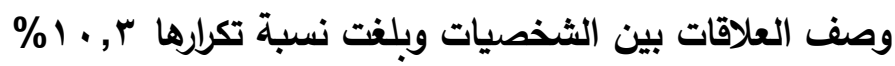
ويتضح من الجدول أن التدريبات والأنشطة تهتم بمهارات مستوى تكوين الدلالات بصورة أقل من مهارات المستوى السابق ويدل ذلك على قلة الاهتمام بتنمية المهارات التي تنشط فكر الطالب العميق مما يساعد على التحليل المستمر ـ مهن

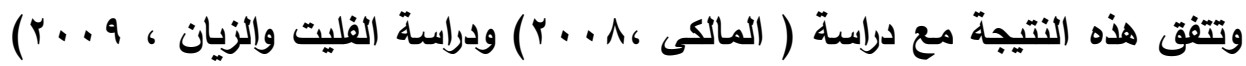

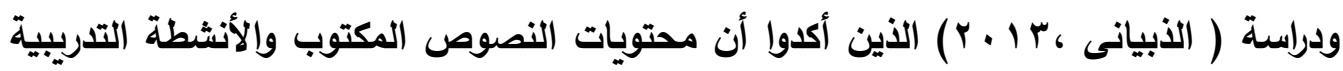
يكون فيها الاهتمام بالمستوى الاستنتاجي او تكوين الدلالات أقل من المستوى الحرفي أو الو

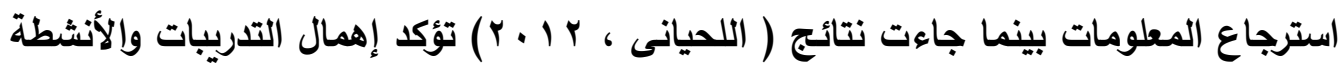
في تنمية المستوى الاستنتاجي أو مستوى تكوين الدلالات . لإِجابة عن السؤال الرابع ونصه : ما درجة توافر مهارات الفهم القرائي ضوء المعايير الدولية للتنور القرائي في كتاب اللغة العربية للصف الأول الثانوي التجاري بمستوى دمج الأفكار وتفسير المعلومات ؟ للإجابة عن السؤال السابق تم رصد وحساب التكرارات والنسب المئوية للتحقق من مدى توافر مهارات مستوى دمج الأفكار وتفسير المعلومات (مستوى الفهم التذوقى ) والجدول التالي يوضح ذلك 
جدول (0) (0)

تكرارات والنسب المئوية لمهارات مستوى دمج الأفكار وتفسير المعلومات

\begin{tabular}{|c|c|c|c|c|c|c|c|c|}
\hline الترتيب & النسب & التكرارات & المئوية & التكراز & المئوية & التكرار & المنسدلة من دمبج الأفكار وتفسير & p \\
\hline$\varepsilon$ & $\%$ & - & $\%$. & . & $\%$. & - & تصديد العبرة الرئيسه & 1 \\
\hline$r$ & $\% 10 . r$ & $r$ & $\%$. & . & $\%$ r. & $r$ & ذفي النص الأكمار المتضانة & r \\
\hline$r$ & $\%{ }^{Y \mu}$ & $r$ & $\%$ \%T.r & 1 & $\%^{r}$. & $r$ & ترتيب الفقرات حسب & $r$ \\
\hline 1 & $\%^{r} \cdot v^{V}$ & $\varepsilon$ & $\%$ \%r.r & 1 & $\%^{r}$. & $r$ & 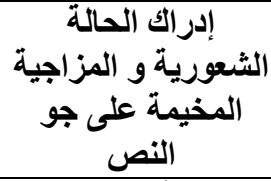 & $\varepsilon$ \\
\hline$r$ & $\% 10 . r$ & $r$ & $\%$ \%T.r & 1 & $\% .1$. & 1 & معنى إلى جملة في ألقّب & 0 \\
\hline$r$ & $\% 10 . r$ & r & $\%$ & - & $\%^{r}$. & Y & ألّراك الكلمات و الجمالية & 7 \\
\hline$\%$ & $1 \ldots$ & 14 & $\% 1 \ldots$ & $r$ & $\% 1 \ldots$ & 1. & المجموع & \\
\hline
\end{tabular}

يتبين من جدول ( •) ومن حساب التكرارات والنسب المئوية لمهارات دمج الأفكار وتفسير المعلومات والتي وردت في كتاب اللغة العربية وجاءت بتكرار ( • (1) في النصوص المكتوبة وتكرار ( r ب) في التدريبات والأنثطة وكانت المهارة الأولى إدراك الحالة المزاجية

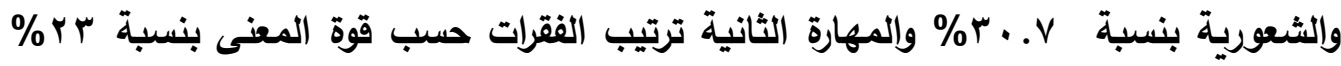

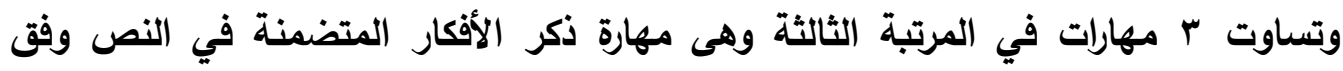

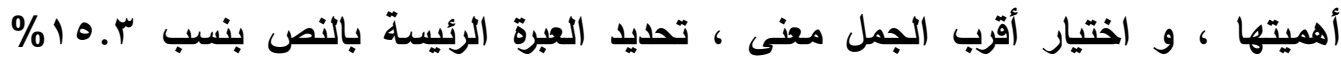
والمهارة الأخيرة كانت تحديد الصور الجمالية في النص وكانت بنسبة ، م ومن خلال الجدول يتضح أن هناك ضعفا في مهارات دمج الأفكار وتفسير المعلومات وهذا يؤكد أن البرنامج القرائى المقدم للصف الأول للمرحلة الثانوية التجارية لا تسهم في تنمية مهارات التفكير العليا 
تقويم مهارات الفهم القرائي في البرنامج القرائي لكتاب اللغة العربية بالصف الأول الثانوي التجاري.........

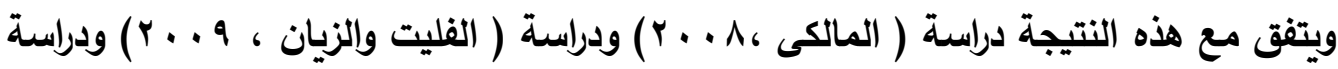

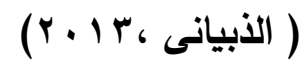

\section{وللإجابة عن السؤال الخامس ونصه}

ما درجة توافر مهارات الفهم القرائي ضوء المعايير الدولية للتنور القرائي في كتاب

اللغة العربية للصف الأول الثانوي التجاري بمستوى تقويم المحتوى واللغة والعناصر ؟ وللإجابة عن السؤال السابق تم رصد التكرارات والنسب في كتاب اللغة العربية من

خلال النصوص المكتوبة والتدريبات والأنشطة المصاحبة وكانت النتائج كما في الجدول التالى

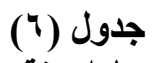

التكرارات والنسب المئوية لمهارات تقويم المحتوى واللغة والعناصر

\begin{tabular}{|c|c|c|c|c|c|c|c|c|}
\hline الترتيب & النسب & التكرارات & المئوية & الأنكرار & المئوية & التكراز & 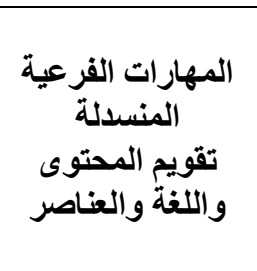 & e \\
\hline 1 & $\%{ }^{\top}{ }^{\top}, \wedge$ & $v$ & $\%$ \% & $\varepsilon$ & $\%$ Yr.r & $r$ & التمييز بين الحقيقة & 1 \\
\hline r & $\% \backslash \wedge . \mid$ & $\varepsilon$ & $\% \backslash \wedge . \mid$ & r & $\% \backslash \wedge, 1$ & r & المعلومات الواردة النصى & r \\
\hline$r$ & $\%$ & - & $\%$ & - & $\%$ & - & المؤلف للموضة نظوع & $r$ \\
\hline 1 & $\%$ & $v$ & $\%$ \% & $\varepsilon$ & $\%$ \% & $r$ & والتلا معقول في التصقول & $\varepsilon$ \\
\hline$r$ & $\% \backslash \wedge . \mid$ & $\varepsilon$ & $\% 9$ & 1 & $\%$ Yr.r & $r$ & ابتكار نهاية مفاجئة & ० \\
\hline$r$ & $\%$ & . & $\%$ & . & $\%$ & - & 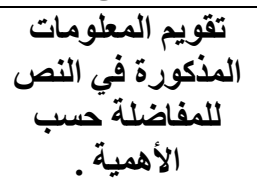 & 7 \\
\hline$r$ & $\%$ & . & $\%$ & . & $\%$ & . & إعادة صياغة النص صحيح . & $v$ \\
\hline \multicolumn{2}{|c|}{$\% 1 \ldots$} & YY & $\% 1 \ldots$ & 11 & $\% 1 \ldots$ & 11 & المجموع & \\
\hline
\end{tabular}




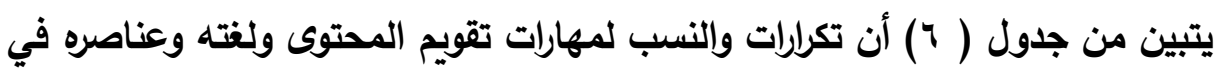

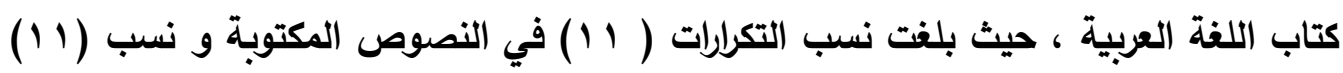

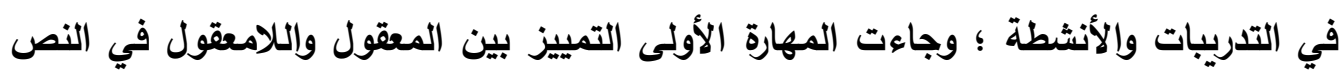

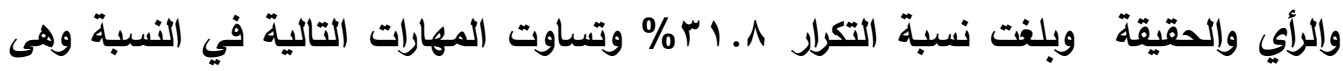

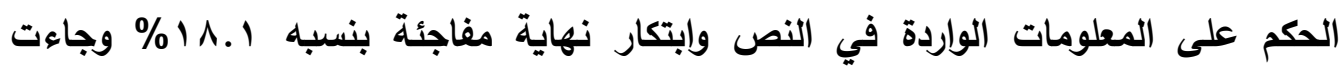

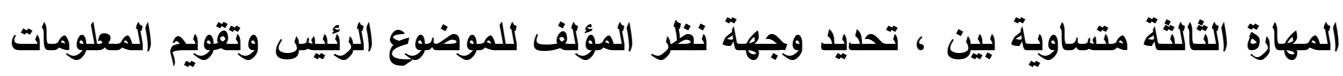

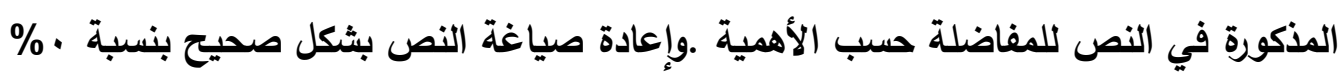

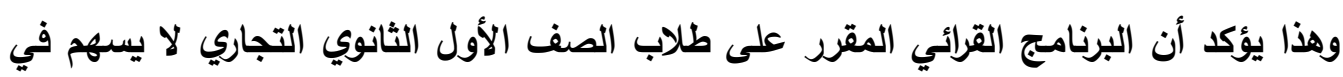

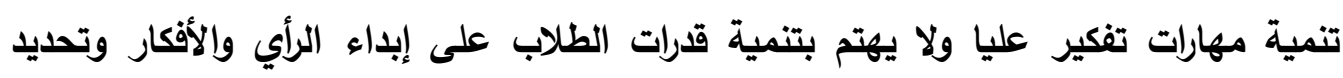

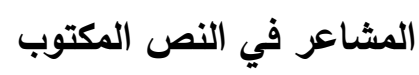

وفى ضوء نتائج البحث جاءت مهارات الفهم القرائي بنسب متفاوتة ، حيث نالت النقات

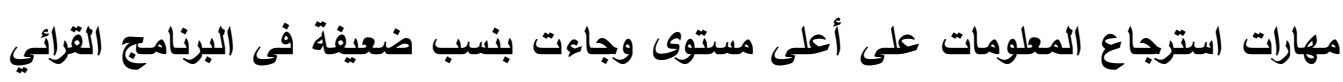

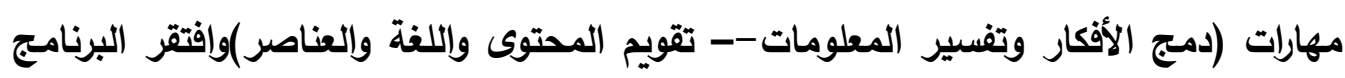

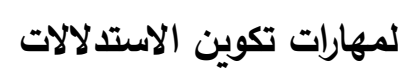

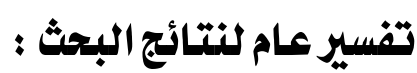
من نتائج البحث السابقة تبين أن هناك افتقار لمهارات الفهم القرائي في ضوء البهائ معايير

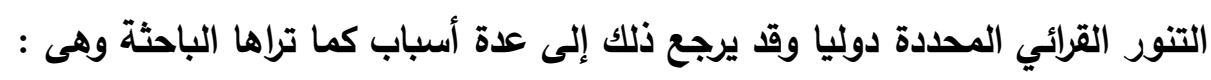

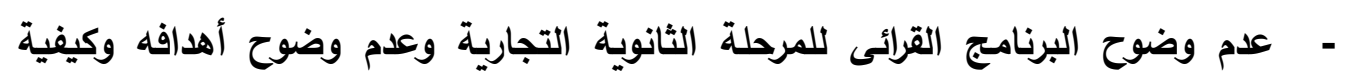
تطبيقه . - علم وجود أدلة ارشادية خاصة للمعلمين والمتعلمين في هذه المرحلة لتوضيح المهارات اللازم تنميتها في هذه المرحلة .

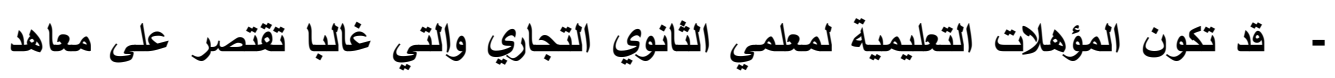

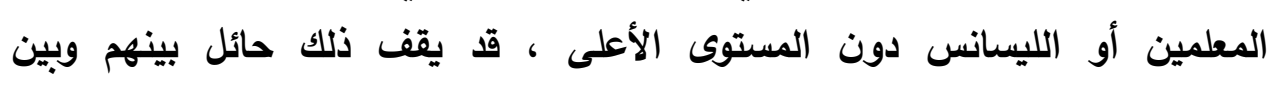

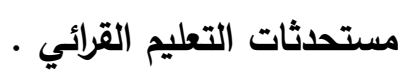
- شعور الكثير من المعلمين بالضجر والضيق نظرا لاكتظاظ الجدول بساعات العمل مما يجعل تنفيذ البرنامج القرائى عبء عليهم . 
تقويم مهارات الفهم القرائي في البرنامج القرائي لكتاب اللغة العربية بالصف الأول الثانوي التجاري............................

- ق قلة دافعية المتعلمين في تعليم مادة اللفة العربية واعتبارها مادة ثانوية بجوار المواد

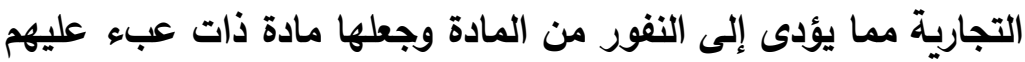

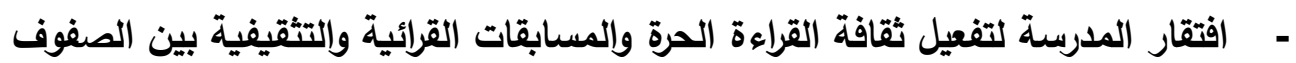
- أتقار ثقاف اكتثاف المواهب الأدبية والقدرات القرائية والكتابية بين طلاب الثانوي التجاري .

- عدم تفعيل الأنشطة المختلفة التي تقوم على القراءة مما يجعلها مادة مهملة . ولإجابة عن السؤال السادس ونصه - ما المخطط التوصيفى المقترح لتنمية مهارات الفهم القرائي في ضوء المعايير الدولية للتنور القرائي بكتاب اللغة العربية لطلاب الصف الأول الثانوي التجاري ؟ من النتائج السابق في الجداول تأكد ضعف مهارات الفهم القرائي في البرنامج القرائي المقدم لطلاب الصف الأول الثانوي ، مما استدعى وضع تصور مقترح لعلاج جوانب الضعف وتدعيم جوانب القوة و تنمية تلك مهارات الفهم القرائي في كتاب اللغة العربية للصف الأول

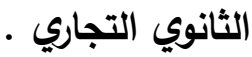
المخطط التوصيفى المقترح لكتاب اللغة العربية بالصف الأول الثانوى التجارى في ضوي PIRLS المعايير الدولية للتنور القرائيى المخطط المقترح يقوم على فكرة الاستفادة من المعايير الاولية للتنور القرائي في تحسين وتطوير المرتكزات الأساسية لمقرر القراءة في المرجلة الثانوية التجارية والتي تتمثل

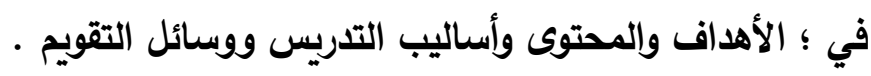
أولا : مبررات المخطط المقتزح أ- قصور منهج اللفة العربية الحالي في تنمية مهارات الفهم القرائى ، كما كشفت نتائج البحث الحالي عن ذلك ، وأكدته نتائج الدراسات والبحوث السابقة التي أجريت في هذا الشأن . ب- ضعف مستوى التنور القرائى في مناهج اللغة العربية في الدول العربية وبين طلاب المدارس في المراحل المختلفة وهذا ما أكدت الدراسات والبحوث التي تم عرضها والتي تمت في قياس التنور القرائي. 


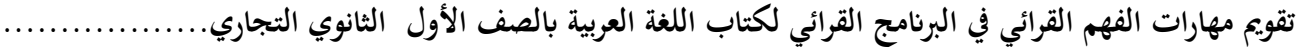

ت- التوسع في استخدام التطبيقات التقنية وتعدد المصادر المعرفية وتطور الوسائل القرائية ، كل ذلك يحتم ضرورة تنمية مهارات الفهم القرائى ووضع خطة للارتقاء بها لمواجهة هذه التطورات ث- التأثيرات الاجتماعية والأخلاقية السلبية التي التعامل معها بوعى وحرص أمرا

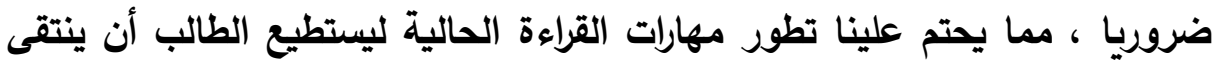
الغث من السمين وفهم المضمون بوعى تام . ج- توصيات معظم البحوث والدراسات التي تناولت تطوير مناهج اللغة العربية ، ونادت بضرورة تنمية مهارات الفهم القرائى فيها ، ومن خلال دمج هذه المهارات في

المناهج الحالية ووضع خطة لتنميتها

ثانيا : المكونات الرئيسة للهخطط المتترح :

أهداف المخطط المقتزح

يسعى المخطط المقترح إلى تطوير البرنامج القرائي المقدم للطلاب في المرحلة

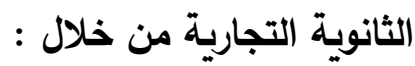
1 - الربط بين ما يكتسبه الطالب من معارف ومفاهيم ومهارات في المنهج الاراسي r- التركيز على مهارات الفهم القرائي وفى ضوء المعايير الدولية لقياس التنور القرائي PIRLS ( استرجاع المعلومات ، تكوين الاستنتاجات ، تفسير ودمج الأفكار والمعلومات

$$
\text { ، تقييم المحتوى ولغته وعناصره ) ـ }
$$

r- اقتراح مجموعة من الدروس ( الأدبية والعلمية ) بجانب موضوعات الوحدة والتي من شأنها أن تساعد على تنمية مهارات الفهم القرائي • ؛ - تضمين نماذج مختلفة لأسئلة الاختبارات الدولية لقياس التنور القرائي ، لتساعد المعلم والطلاب على التدريب على مهارات القراءة ومحاكتها إثناء إعداد الاختبارات الثهرية

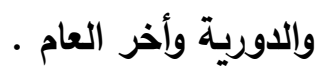

\section{مصفوفة المخطط المقتزح}

شملت مصفوفة المخطط المقترح للصف الأول الثانوي التجاري مجموعة الدروس المقترحة لكل معيار وما يتناسب مع كل درس من أنشطة واستراتيجيات وتقويم ونعرضها 


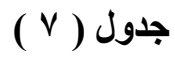

مصفوفة المحتوى المقترح لتنمية مهارات الفهم القرائي في ضوء المعاييز الدولية للتنور القرائي

\begin{tabular}{|c|c|c|c|c|c|c|}
\hline التقويم & الأنشطة & الاستراتيجيات & المعلوماتية & الموضوعات الأدبية & المهارات المستهذف تنميها & الدارس \\
\hline \multirow[t]{4}{*}{ 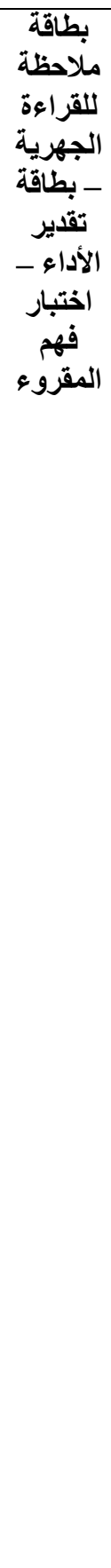 } & كتابة مقالة & النعالنى التعلى & & ليلة لا تنسى & 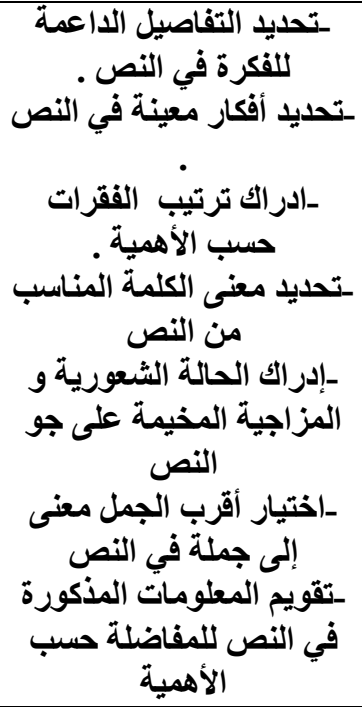 & الأول \\
\hline & النوم عنيع & والعناقشة & الفضّى في & & - & الثانى \\
\hline & متكررة & القصة & & الفتاة الذكية & 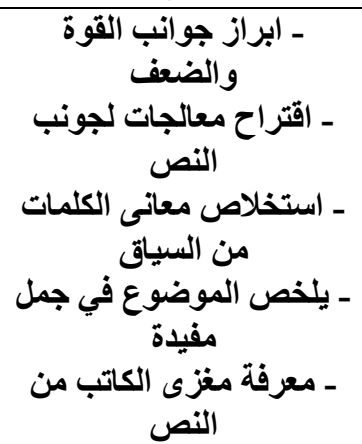 & الثالث \\
\hline & المعلوميصت & والمناقشة & الأهزامات & & ـ ـ ـترتيب بين الأفكار حبقة والخيال & الرابع \\
\hline
\end{tabular}




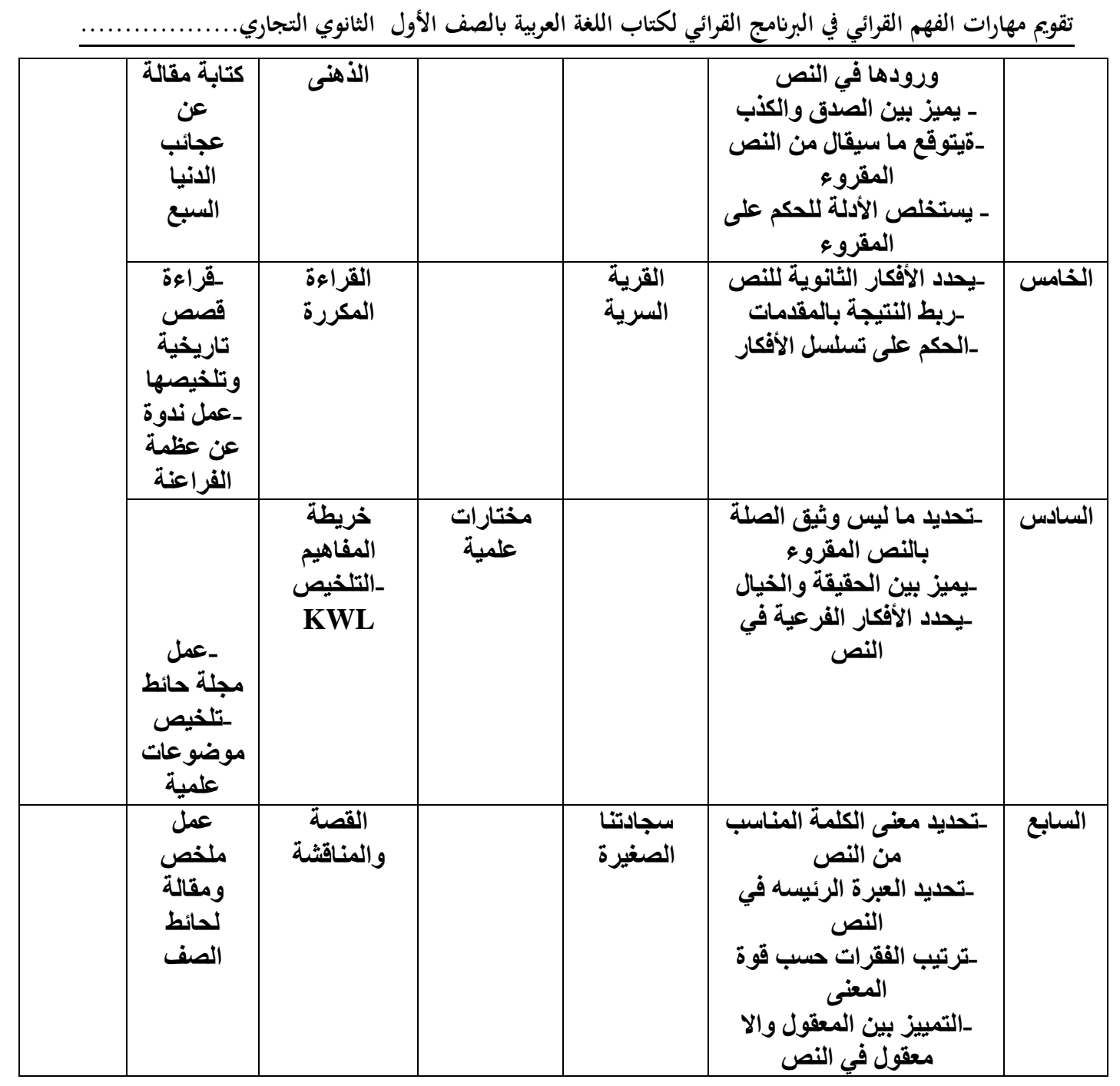

\section{توصيات البحث : ت ت}

في ضوء ما أسفرت عنه البحث من نتائج يمكن تقديم التوصيات التالية : - ضرورة دعوة القائمين على التعليم الفني من تخطيط المناهج وبنائها ؛ إلى تطوير نشاط التعلم وتعزير مهارات الفهم القرائي والاهتمام بها والإفادة من قائمة المهارات

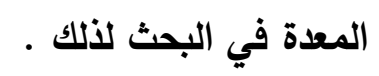
- ضرورة الاهتمام بالأنثطة وإلتدريبات لمهارات الفهم القرائي وخاصة المهارات العليا لها من تذوق ونقد وعدم التركيز على مهارات دون الأخرى . 
- أهمية لفت انتباه القائمين على التعليم الفني بضرورة تضمين مهارات الفهم القرائي في البرنامج القرائي المقدم لهذه الفئة لتساعدهم على النمو الشامل والمتوازن

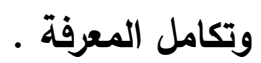
- الاطلاع على اختبار بيرلز المطبق في الدول المشاركة والاستفادة من طريقة عرض الأسئلة والمادة المقروعة على التبارة - إعادة النظر في صياغة الأنشطة والتدرببات والنصوص المكتوبة بما يخدم الدراسة الاولية بيرلز - تصميم كراسة للأنثطة والتدريبات منفصله عن محتويات كتاب اللغة العربية ومرتبطة بموضوعاته ، تحاكى نماذج تدريبات واختبارات الدراسة الدولية بيرلز مقترحات البحث

في ضوء نتائج البحث السابق يمكن اقتراح إجراء البحوث التالية : - مدى إلمام معلمي اللفة العربية بالمراحل الفنية بطرق واستراتيجيات تنمية مهارات إنداء

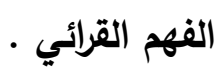
- إجراء دراسات تقويمية في مراحل دراسية أخرى في ضوء المعايير الدولية للتنور القرائي بيرلز الجزاء دراسيات - قياس المعايير الدولية للتنور القرائي على صفوف دراسية مختلفة وأثرها على تنمية مهارات التفكير العليا. 


\section{المراجع}

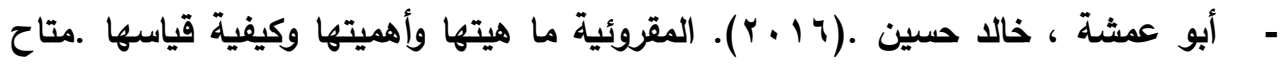
على $b^{r} \cdot 19 / \mathrm{V} / \mathrm{rq}$

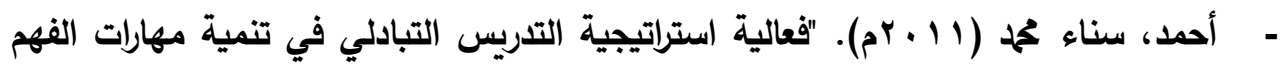

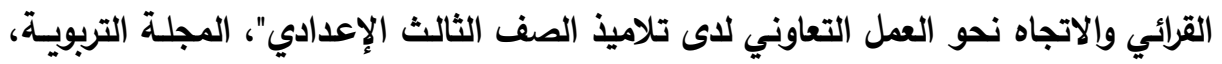
كلية التربيـة بسوهاج، العدد (و ب ) ).

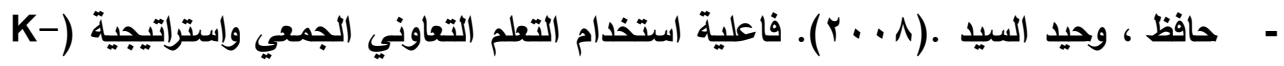

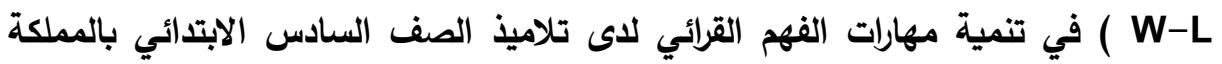

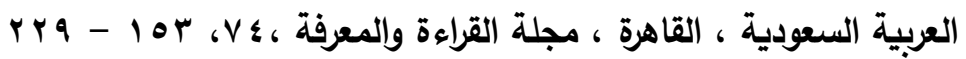

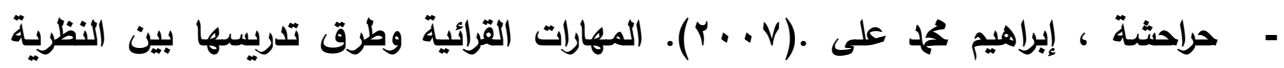

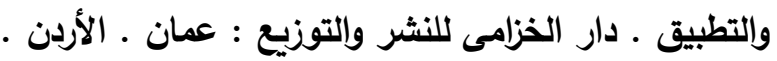

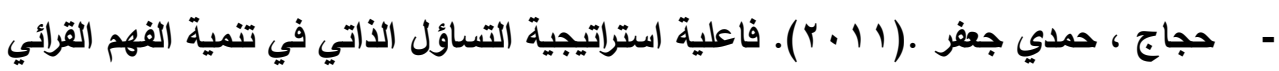

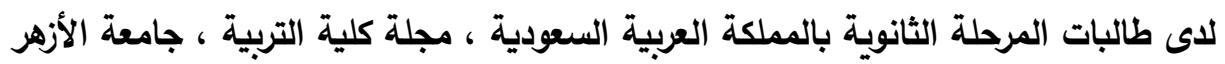

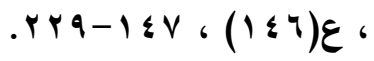

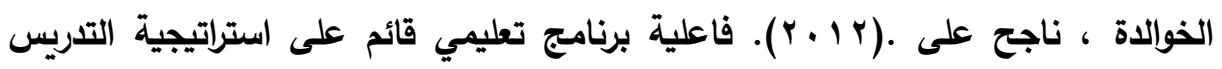
التبادلي لتنمية مهارات الفهم القرائي لذوى صعوبات التعلم بالمرحلة الأساسية في الأردن .

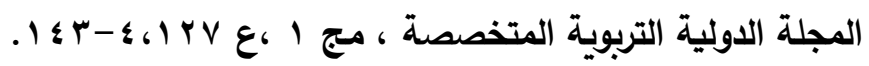

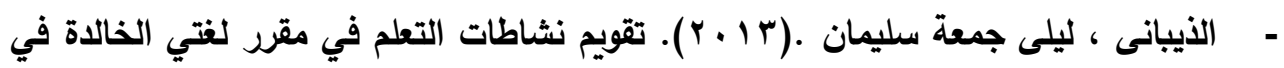

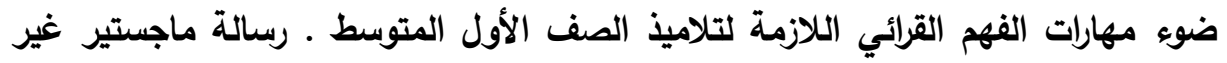

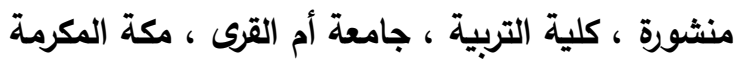

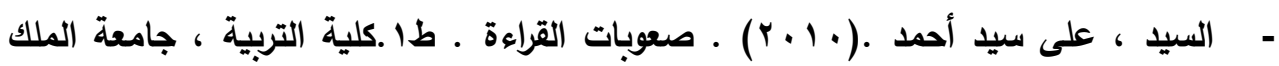

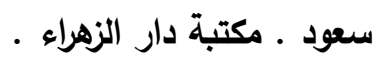
- شبارة ، أحمد مختار .( (99 19). دور مناهج العلوم الطبيعية والبيولوجية في تنمية قدرات

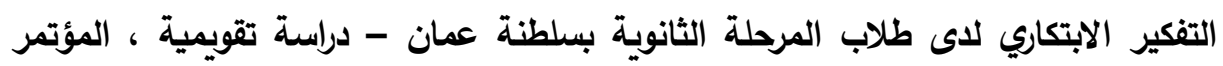

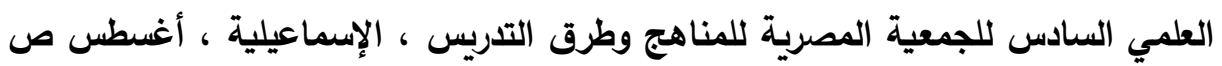




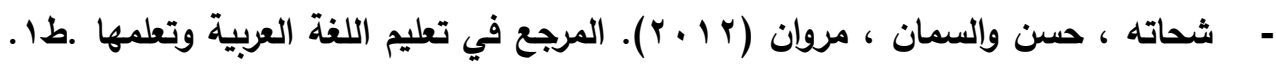

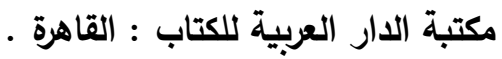

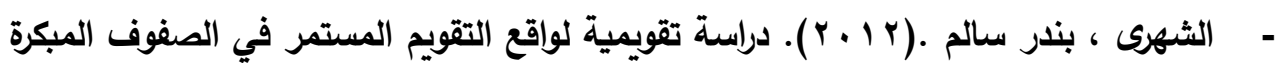

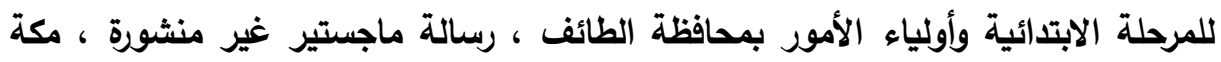
المكرمة ، كلية التربية : جامعة أم القرى .

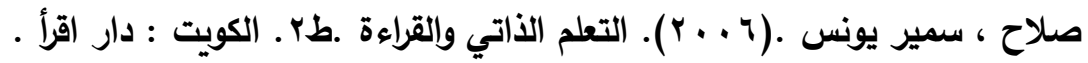

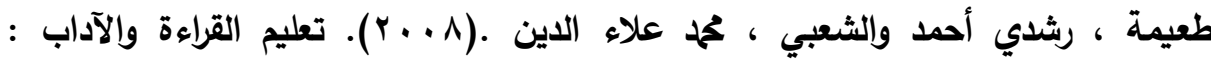
استراتيجيات مختلفة كمجهود متنوع .دار الفكر العربي : القاهرة .

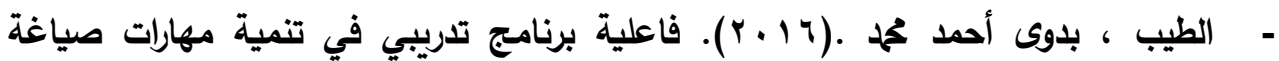

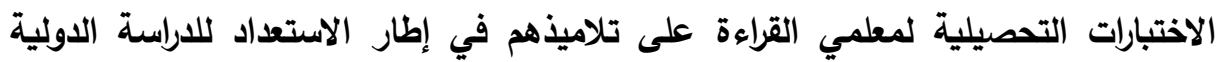
( PIRLS)

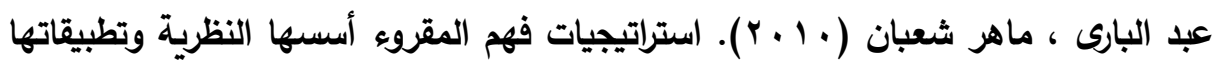

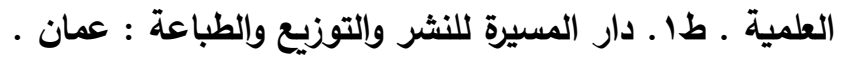

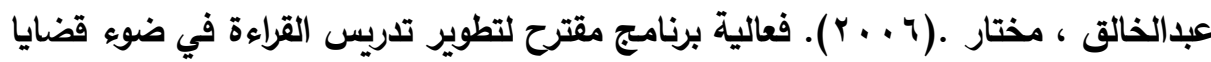

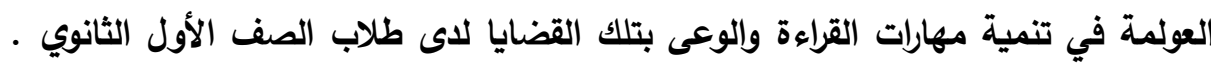
رسالة دكتوراه غير منشورة ، كلية التربية ، جامعة المنيا .

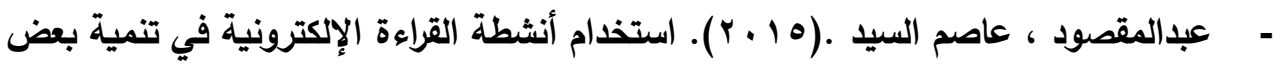

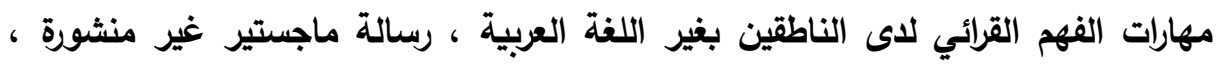

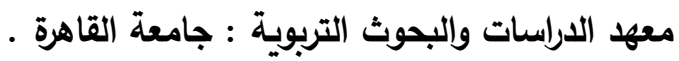

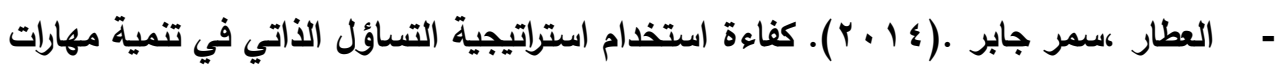
تفسير المقروء ونقده لاى تلاميذ الصف الأول الإعدادي ، رسالة ماجستير غير منشورة ، كلية التربية : جامعة قناة السويس .

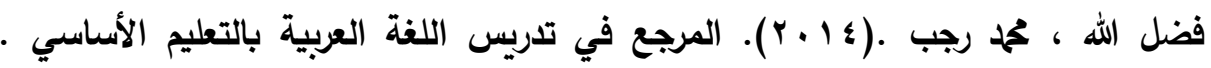

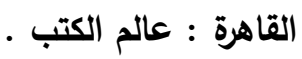

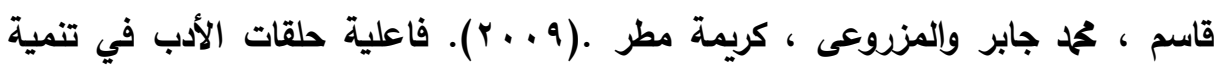

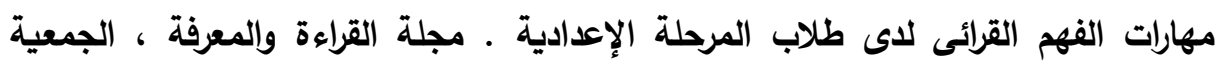

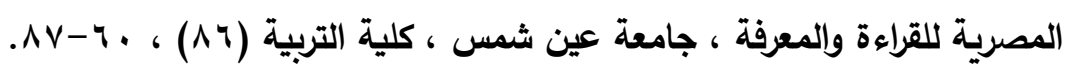




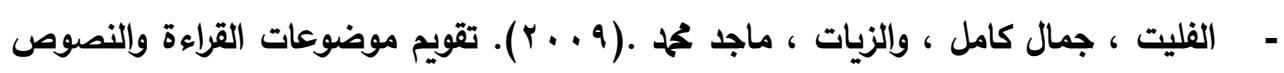

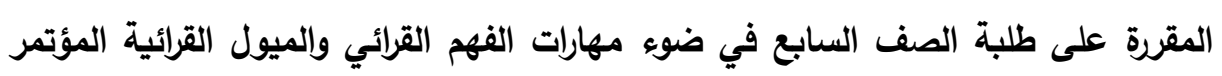

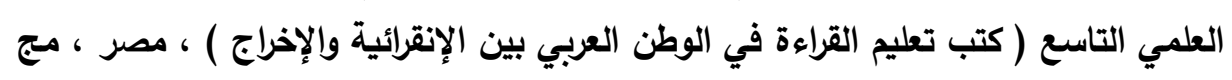

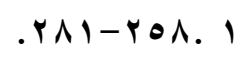

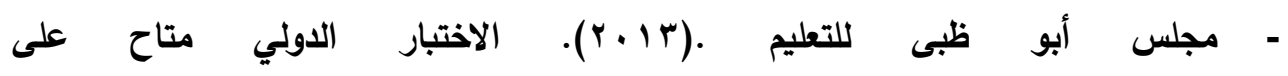

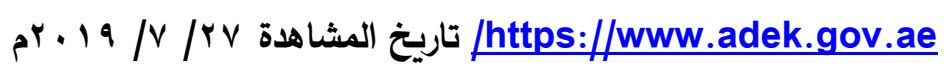

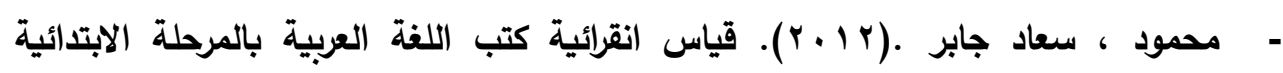

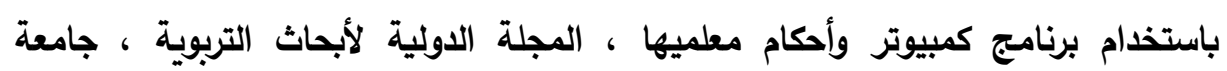

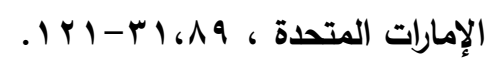

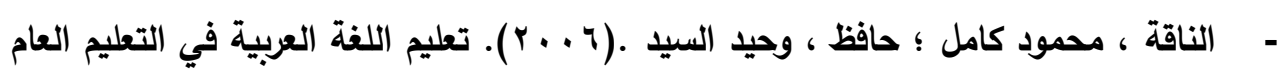

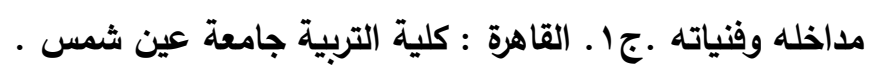

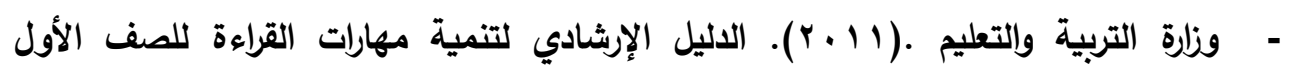

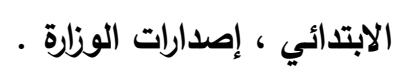

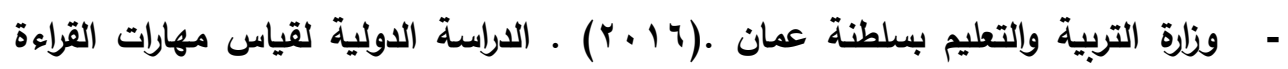

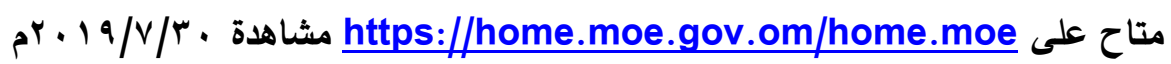
AI-Alwan,A. $(r \cdot 1 r)$. The Effect of Using Metacognition Reading Strategies on the Reading Comprehension of Arabic Texts Intermediate Journal of Applied Educational Studies . No. $1 \uparrow, 1-1 \wedge$.

-Alexander, P. A., \& Jetton, T. L. (... ). Learning from text: A multidimensional and developmental perspective. In M.L. Kamil, P. Mosenthal, P. D. Pearson, \& R. Barr (Eds.), Handbook of reading research (Vol. r) (pp. $\left.\nmid \wedge \bullet_{-}\right)^{\prime} \cdot$ ). Mahwah, NJ: Lawrence Erlbaum Associates .

-Beach, R., \& Hynds, S. ( $१$ १४). Research on response to literature. In R. Barr, M. L. Kamil, P. Mosenthal, \& P. D. Pearson (Eds.), Handbook of reading research (Vol. r) (pp. $\leqslant \diamond \uparrow-\varepsilon \wedge q)$. Mahwah, NJ: Lawrence Erlbaum Associates.

-Burt, angela.$(r \cdots \bullet)$. Key comprehension new edition teacher's hand books $r$,Jordan : Ginn.

-Clay, M. ( $(99$ १). Becoming literate: The construction of inner control. Auckland, New Zealand: Heinemann.

-Hall, K. ( (११^). Critical literacy and the case for it in the early years of school. Language, Culture and Curriculum, $11,1 \wedge r_{-} 19 \varepsilon$. 


$$
\text { تقويم مهارات الفهم القرائي في البرنامج القرائي لكتاب اللغة العربية بالصف الأول الثانوي التجاري. }
$$

-Huang , Y.(Y.11). A Study of Social Media Impact on Metacognition in an Online Inquiry Learning Activity . Journal of Next Generation Information Technology ( JNIT), No. $\varepsilon, r \varepsilon-\uparrow$.

-Lipka , O, Sigel , S, $\left(r \cdot \varphi^{\bullet}\right)$. The Improvement of Reading Skills of $L \perp$ and ESL Children Using a Response to Intervention (RTI) Model . Psicothema, VoI . r r, No, $\{, q \ldots q$, $q$ r.

- Meissner , J.\&Yun , T.C. $(\uparrow \ldots \wedge)$ Verbal Solution Guide . Manhattan: Manhattan Review.

-Spruce ,R. $(r+1 r)$. Teacher Beliefs , Knowledge, and Practice of Metacognition and Self - regulated Learning Old Dominion University Press.

-Teng,Y. $(\uparrow \ldots q)$. The Relationship of Reading Methods and Hearing Styles to Taiwanese $1 r$ th Grade Male Students Reading Comprehension in English .PHD. Thesis, The Faculty of Education . san Francisco.

-Westword,P. $(r+\mid r)$. Reading and Learning Difficulties Approaching teaching and Assessment . Divid Fulton Publisher . 